\title{
Validation of the Critical Shear Crack Theory for punching of slabs without transverse reinforcement by means of a refined mechanical model
}

\author{
João T. Simões @ । Miguel Fernández Ruiz @ | Aurelio Muttoni
}

École Polytechnique Fédérale de Lausanne, School of Architecture Civil and Environmental Engineering, Station 18, CH-1015, Lausanne, Switzerland

\section{Correspondence}

João T. Simões, School of Architecture, Civil and Environmental Engineering, École Polytechnique Fédérale de Lausanne, Station 18, CH-1015,

Lausanne, Switzerland.

Email: joao.simoes@epfl.ch
Despite the intensive efforts dedicated in the last decades to better understanding punching shear failures, there is still no consensus on the mechanics governing this phenomenon and on how to implement it within a physical approach. In this paper, an analysis of recent detailed measurements on the kinematics and crack development associated with punching failures is presented. This allows classifying the observed cracks by their nature and to address their interaction and development on the eventual punching failure surface. On this basis, a complete mechanical model is formulated consistently with the principles of the critical shear crack theory (CSCT). This model generalizes previous approaches based on the CSCT by accounting for the various crack types and failure modes as well as for their associated kinematics. The generality of the model is verified by extensive comparisons to test data, showing accurate and consistent agreement. Its results are eventually used to investigate the role of the various potential sheartransfer actions as well as the pertinence of the assumptions adopted to simplify the CSCT by describing its failure criterion with analytical expressions.

\section{KEYWORDS}

concrete structures, Critical Shear Crack Theory (CSCT), experimental verification, failure criterion, members without transverse reinforcement, punching shear strength

\section{1 | INTRODUCTION}

Punching shear failures were early identified as a governing failure mode in reinforced concrete flat slabs, and their first designs accounted for this fact by introducing column capitals and mushroom-shaped columns. Intensive research performed since the second half of the 20th century ${ }^{1-4}$ led eventually to the development of design expressions allowing to evaluate the punching shear capacity accounting for the role of some relevant mechanical and geometrical parameters. ${ }^{5-9}$ These expressions, with an empirical basis

Discussion on this paper must be submitted within two months of the print publication. The discussion will then be published in print, along with the authors' closure, if any, approximately nine months after the print publication. and at the origin of those provided still today in many codes of practice, ${ }^{10,11}$ had however a validity limited to the available experimental data at the time they were proposed. Theoretical approaches were later developed, on the basis of limit analysis (e.g., References 12 and 13), fracture mechanics (e.g., Reference 14) or accounting for mechanical models (e.g., Reference 15-24).

The theoretical approaches constituted a major step toward the consistent understanding of the phenomenon and the treatment of some important issues such as the size and strain effects. ${ }^{25}$ Among these models, one of the most notable contributions was that by Kinnunen and Nylander, ${ }^{15}$ relating the deformation and load-carrying capacities of slab-column connections failing by punching. The model 
considers that the punching strength is controlled by a conical shell representing the inclined compression struts developing at the support of the column. Failure in this region was assumed to be triggered by a limit value of the tangential strain in the compression zone, calculated for a given level of load on the basis of a conically deformed shape of a slab sector. ${ }^{15}$ The physical principles of this model led to a notable acceptance of the research community and inspired a number of researchers that improved the original approach. For instance, Hallgren ${ }^{20}$ proposed an improved failure criterion to account for the influence of size effect and concrete brittleness. Broms ${ }^{17-19}$ proposed also an improvement of the theory by considering two different failure criteria based on limit tangential and radial conditions (representing different failure modes for slender and squat members). A similar approach to that of Broms ${ }^{17-19}$ was also followed by Shehata and Regan ${ }^{16}$, considering three failure criteria, representing each a different failure mode (splitting of concrete strut and crushing of concrete due to high radial or tangential strains).

Inspired on the rational approach of Kinnunen and Nylander, ${ }^{15}$ Muttoni and Schwartz ${ }^{21}$ developed a mechanical model for punching shear failures, named as the critical shear crack theory (CSCT). ${ }^{22}$ According to this theory, which is also applicable to shear in beams (e.g., Reference 26-29), the opening of a critical shear crack (CSC) (a crack in the shear-critical region where the compression strut carrying shear develops) reduces the ability of concrete to transfer shear forces and leads eventually to failure. ${ }^{22} \mathrm{On}$ that basis, a failure criterion relating the maximum allowable shear force that can be transferred for a level of crack opening (related to the slab rotations) was defined, ${ }^{22}$ refer to Figure 1a. The punching failure load and its associated deformation capacity can thus be calculated by intersection of the failure criterion with a load-rotation relationship (relating the opening of the cracks with the level of applied load), refer to Figure 1b.

As explained by Muttoni et $\mathrm{al}^{30}$, the opening of the CSC as a function of the acting load is associated with the rotation of the slab $(\psi)$ and also to its shear deformations $\left(\delta_{s}\right)$, see Figure 1c. Several approaches have been proposed in the past to perform a refined calculation of the failure criterion consistently with the hypotheses of the CSCT. According to these approaches, the opening of the CSC and its associated shear capacity (resulting from the stresses developed, refer to Figure 1d) can be calculated on the basis of the shape of the failure surface and its kinematics (a detailed review can be consulted in Muttoni et $\mathrm{al}^{30}$ ).

For slender members, refined calculations of the failure criterion of the CSCT have been proposed on the basis of a simplified shape and kinematics of the failure surface. A complete approach for so doing was first developed by Gui$\operatorname{dotti}^{31}$ and some improvements were later added by Clément. $^{32}$ As shown in Figure $2 \mathrm{a}$, Guidotti ${ }^{31}$ considered the CSC as a conical surface (inclined at $45^{\circ}$ ) and a kinematics defined by a rotation around the tip of the crack (column

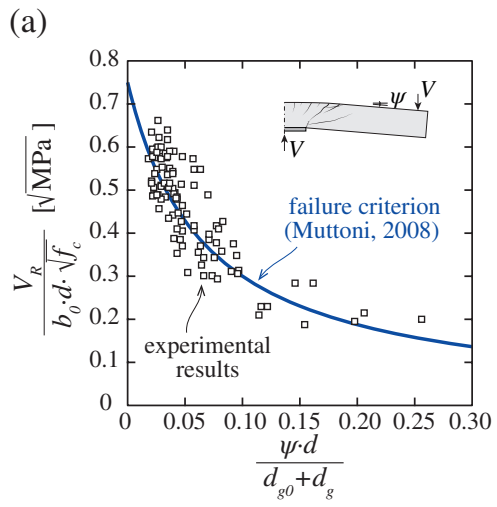

(b)

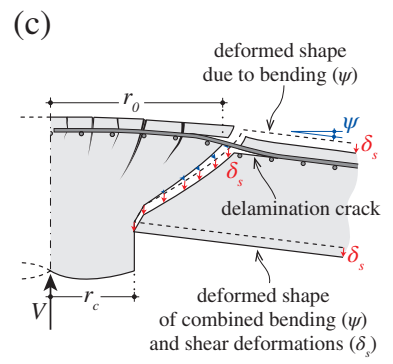

(d)
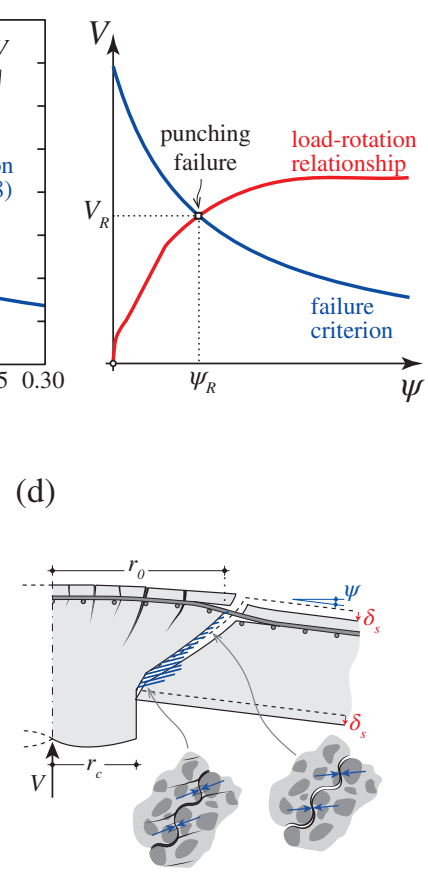

FIGURE 1 Mechanical model of the Critical Shear Crack Theory (CSCT): (a) experimental validation of the hyperbolic failure criterion of CSCT (experimental data from Muttoni ${ }^{22}$ ); (b) calculation of punching shear failure by intersecting the load-rotation relationship and the failure criterion; (c) adopted kinematics at failure and (d) resulting internal forces along the critical shear crack; figure adapted from Muttoni et al ${ }^{30}$

perimeter) and a constant shear deformation. The shear strength can thus be calculated by integration of the aggregate interlock and residual tensile strength contributions. As discussed by Muttoni et $\mathrm{al}^{30}$, the results of Guidotti ${ }^{31}$ show that, at failure, the shear strains $\left(\delta_{s}\right)$ are correlated to the rotations $(\psi)$, and thus the punching shear strength for slender members can be expressed as a function of the rotations of the slab (as proposed by the failure criterion of the CSCT, see Figure 1a). The approach of Guidotti ${ }^{31}$ has been observed to be more suited for slabs experiencing large rotations (thin and slender slabs with medium to low amounts of flexural reinforcement), where bending deformations govern the CSC width. ${ }^{30}$ However, when the thickness of the compression zone is relatively large (prestressed slabs or

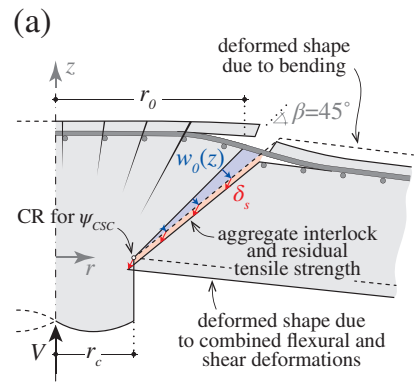

(b)

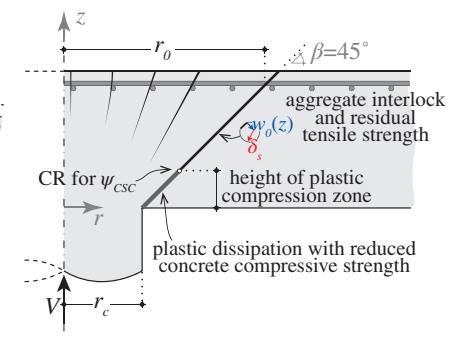

FIGURE 2 Mechanical models consistent with the theoretical principles of the CSCT proposed by (a) Guidotti ${ }^{31}$ and (b) Clément ${ }^{32}$ 
slabs with fairly large reinforcement amounts), these assumptions need to be refined. These additional considerations were later implemented by Clément, ${ }^{32}$ who considered the CSC composed by two conical surfaces with different responses (Figure 2b). The limit between these surfaces was considered to be given by the height of the plastic compression zone and is thus influenced by the presence of in-plane forces and the flexural reinforcement ratio. For the upper conical surface, Clément ${ }^{32}$ considered a similar response as Guidotti. ${ }^{31}$ For the lower part, the contribution to the punching strength was estimated with the kinematical theorem of limit analysis based on the work of Braestrup et al. ${ }^{12}$ and considering an effective concrete compressive strength function of the bending deformations. The enhancement of the CSCT by Clément ${ }^{32}$ has nevertheless some limitations, as it leads to a discontinuous displacement field along the failure surface.

For squat slabs or footings, where the role of the shear deformations is more dominant, ${ }^{33}$ Simões et al. ${ }^{34}$ determined the shape of the failure surface and its associated kinematics based on limit analysis. In this case, the punching strength is calculated assuming a rigid-plastic behavior of concrete characterized by an effective concrete compressive strength accounting for the crack opening (in agreement with the CSCT principles).

Despite the fact that all the mentioned works ${ }^{31,32,34}$ share the principles of the CSCT, they were developed to address particular cases. Within this context, the present paper is aimed at introducing a comprehensive mechanical model for punching of slabs without transverse reinforcement consistent with the CSCT principles $^{30}$ and with the crack development and kinematics measured in tests. This model generalizes the approaches of Guidotti ${ }^{31}$ and Clément $^{32}$ and allows investigating members with large and low levels of flexural deformation (an extended discussion for squat members will not be presented in this paper and can be consulted elsewhere $)^{35}$. Extensive comparisons with available data as well as detailed investigations of selected specimens validate the presented refined calculation of the failure criterion. Finally, the theoretical results are used to discuss the main assumptions and limits of applicability of the analytical failure criterion of the CSCT.

\section{I ANALYSIS OF THE PUNCHING SHEAR BEHAVIOR BASED ON EXPERIMENTAL OBSERVATIONS AVAILABLE IN THE SCIENTIFIC LITERATURE}

\section{1 | Discussion on the cracking pattern observed in the saw-cuts of tested specimens}

Detailed measurements on the development of cracks within reinforced concrete members have recently been performed for beams in shear (e.g., Reference 26,36,37). These measurements have shown to be instrumental for the understanding of the mechanisms leading to shear failures and the role of the various shear-transfer actions (e.g., Reference 26,36,37). As discussed by Einpaul et al, ${ }^{38}$ such measurements cannot be easily performed for punching failures and the knowledge on their crack development remains limited. An attempt to obtain direct measurements inside the slab was performed by Clément, ${ }^{32}$ Einpaul, ${ }^{39}$ and Einpaul et al, ${ }^{38}$ by using an innovative measuring system based on a robotic arm, reading the location of target points inside the slab (accessible by means of narrow holes). Based on these measurements, the authors could track the development of inner cracking and calculate relative crack displacements and directions at different load stages.

On that basis, Clément, ${ }^{32}$ Einpaul, ${ }^{39}$ and Einpaul et al. ${ }^{38}$ identified different types of cracks related to punching failures. The CSC, as previously described by Muttoni, ${ }^{22}$ corresponds to a tangential crack with flexural origin that develops in a stable manner and whose presence disturbs the compression strut-carrying shear. As described by Clément, ${ }^{32}$ Einpaul, $^{39}$ and Einpaul et al, ${ }^{38}$ the failure crack (eventual surface of failure) may be coincident with the CSC, partly coincident with it or completely different. In this latter case, it corresponds to a crack that propagates in an unstable manner from the compression side with a flat inclination angle (Clément, ${ }^{32}$ Einpaul, ${ }^{39}$ and Einpaul et al $^{38}$ ).

In addition to the CSC and failure crack, other cracking types can typically be observed in slabs failing by punching shear. Following a similar systematics and notation to the one proposed by Cavagnis et $\mathrm{al}^{26}$ for beams in shear, the cracks that can be observed after a punching failure may be differentiated according to their location, shape, and origin (Figure 3):

- Cracks type A are associated with a flexural origin, originated on the tension side and propagating toward the compression side in an inclined manner due to the shear forces (as described by, for example, $\mathrm{Moe}^{7}$ and Muttoni, ${ }^{22}$ refer to Figure 3a). Cavagnis et $\mathrm{al}^{26}$ also distinguished between primary and secondary flexural cracks. While secondary flexural cracks develop only at the height of the flexural reinforcement (controlled by bond conditions), the primary flexural cracks are those propagating toward the neutral axis. ${ }^{26}$

- Cracks type B are associated with the formation of a shear band with several parallel cracks that eventually coalesce in one single crack, refer to Figure $3 b .{ }^{30}$ This type of cracking normally develops close to failure, near the column support in the soffit of the slab (see, Reference 38). In the case represented in Figure 3b, this cracking type joins the column edge to a crack type A but it can also develop only partially, followed by the propagation of a crack type $\mathrm{F}$ or $\mathrm{F}^{\prime}$, see Figure $3 f$. 
(a)

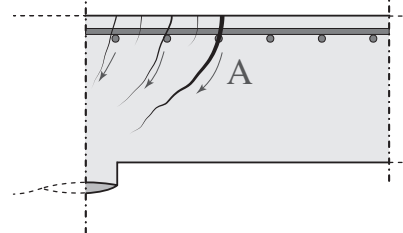

(c)

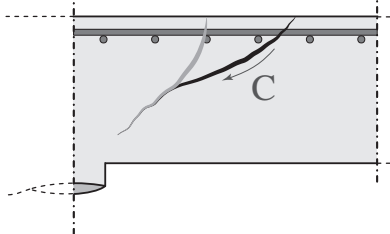

(e)

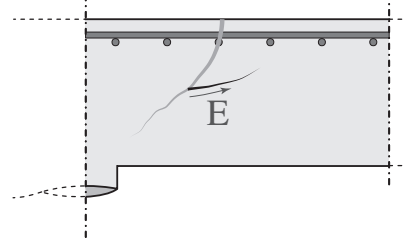

(g)

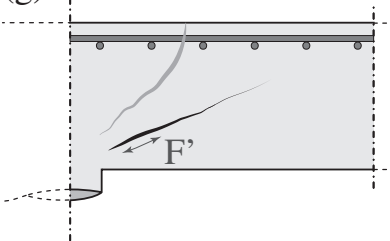

FIGURE 3 Different cracking types observed in a saw-cut of a punching test

- Cracks type $\mathrm{C}$ represent cracks with flexural origin developing in an inclined manner and that merge to a previously formed crack type A, influencing the shape of the CSC (refer to Figure 3c). This type of crack has been previously observed in one-way shear tests by Cavagnis et $\mathrm{al}^{26}$ and in two-way shear tests by Einpaul et $\mathrm{al}^{38}$

- Cracks type D represented in Figure 3d result from delamination of the concrete top cover due to dowelling of the flexural reinforcement bars (cracking type previously identified by, e.g., Krefeld and Thurston, ${ }^{40}$ Fernández Ruiz et al, ${ }^{41}$ Fernández Ruiz et al, ${ }^{42}$ Cavagnis et al, ${ }^{26}$ and Einpaul ${ }^{39}$ ).

- Cracks type E have been originally identified by Cavagnis et $\mathrm{al}^{26}$ to develop in one-way members originating from cracks type $\mathrm{A}$, due to high local aggregate interlock stresses (when the shape of the crack is very favorable to aggregate interlock engagement, see Reference 43; Figure 3e).

- Cracks type $\mathrm{F}$ and $\mathrm{F}^{\prime}$ correspond to unstable splitting cracks developing near the supported area and propagating toward the flexural reinforcement with a flat inclination, as described by Clément, ${ }^{32}$ Einpaul $^{39}$ and Einpaul et $\mathrm{al}^{38}$ (refer to Figure 3e,f). Cracks type F develop from the shear band (crack type B, see Figure 3f), while cracks $F^{\prime}$ develop without the presence of a shear band (Figure 3e). Their distinction is however not neat in many cases. They also have the same origin: cracks type $F$ result from the strain and stress state in the shear band (yielding an unstable splitting crack propagation toward the flexural reinforcement, refer to specimen PE9 in Figure $4 b$ ), while cracks of type $\mathrm{F}^{\prime}$ develop as a consequence of the tensile strains near the supported area (refer to specimen PF21 in Figure 4b) which result also from the kinematics of the region of the slab at the potential location of the shear band.

All types of cracks previously introduced in a qualitative manner in Figure 3 are generally present in a combined manner in the saw-cut of slabs failed by punching shear. Figure 4 (pictures and details with interpretation of observed cracking types) shows some instances for selected saw-cuts of slabs without in-plane forces (PG-3 of Guandalini, ${ }^{44}$ PG20 and PG29 of Guidotti, ${ }^{31}$ PE6, PE9, and PE10 of Einpaul $^{39}$, PF21 of Clément ${ }^{32}$ ). It can be noted from these figures that:

- Several cracks with flexural origin (cracks A) develop from the tension side toward the compression side (some may however have closed during unloading after failure and are hardly visible or not visible in the saw-cuts).

- Cracks with flexural origin developing further away from the column (cracks type C) are observed to govern the shape of the CSC in some cases (if merging to other flexural crack, PG29 and PF21 in Figure 4) but not in others (not merging, PE9 in Figure 4). In the latter case, the CSC is a crack type A with an average inclination of about $45^{\circ}$, whereas in the former case the CSC is composed by a crack type $\mathrm{C}$ merged with a crack type $\mathrm{A}$, thus reducing its average inclination.

- Cracks type B (associated with the shear band) may be observed in most of the saw-cuts. In some cases, cracks type $\mathrm{B}$ join the edge of the column and the tip of one crack type A (PG-3 and PG20 in Figure 4). In other cases, cracks type B start developing, but failure is controlled by the propagation of a crack type $\mathrm{F}$ or $\mathrm{F}^{\prime}$ (PE6 and PE9 in Figure 4). In these cases, even if a crack of type $\mathrm{F}$ or $\mathrm{F}^{\prime}$ develops, a region of cracks type $\mathrm{B}$ can often be identified near the column.

- Cracks type B often present a steeper inclination than cracking type $\mathrm{A}$ and $\mathrm{C}$, see PG-3, PG20 and PE6 in Figure 4.

- Specimen PE10 in Figure 4 shows an example of a crack type $\mathrm{E}$, which probably developed due to the shape of the upper part of the CSC (quasi-vertical branch favorable to engage aggregate interlock forces). Similar observations have already been made by Cavagnis et $\mathrm{al}^{26}$ in one-way shear tests.

- Cracks type D can often be recognized at the level of the flexural reinforcement (associated with delamination of the thereof; see PG20, and PG29 in Figure 4). 
(a)
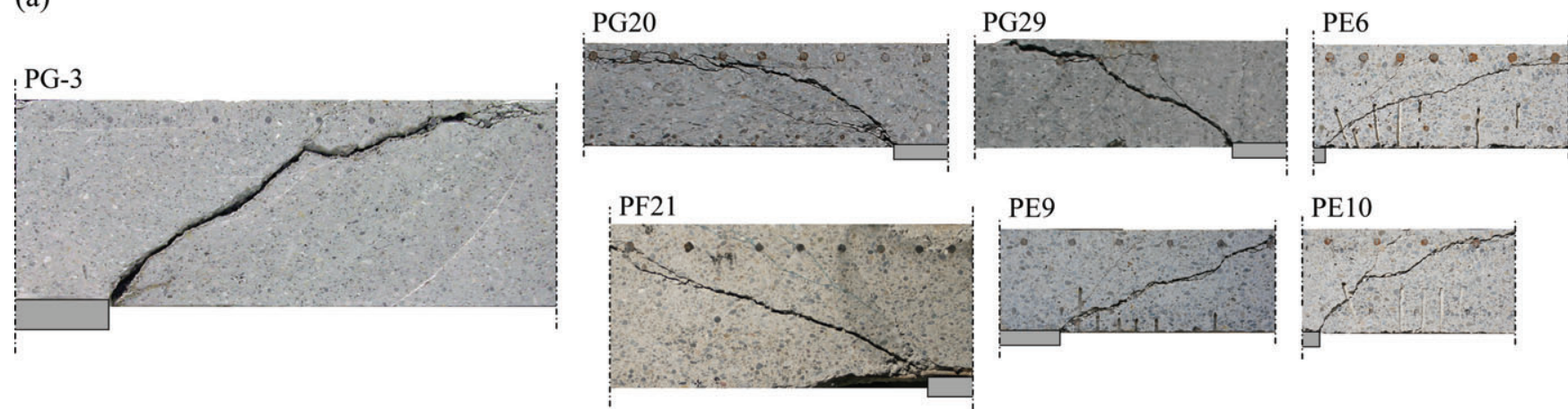

(b)
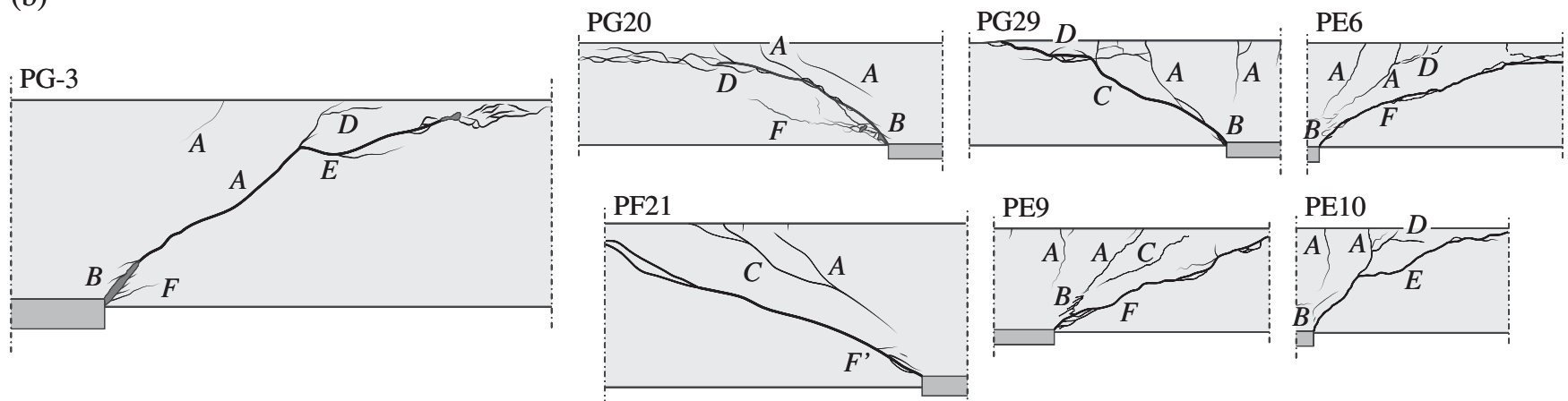

FIGURE 4 Saw-cuts of tested slabs: (a) pictures and (b) interpretation of observed cracking; specimens $\left(B / d=8.6-14.9 ; r_{q} / d=4.3-7.5\right.$; $\left.d=0.201-0.456 \mathrm{~m} ; c=0.22-0.52 \mathrm{~m}, r_{c}=0.083-0.166 \mathrm{~m}\right)$ : PG3 ${ }^{44}$; PG20 and PG29 of Guidotti ${ }^{31}$; PE6, PE9, and PE10 of Einpaul ${ }^{39}$ and PF21 of Clément $^{32}$

According to the analysis of the cracking pattern of the saw-cuts, and as already discussed by Einpaul et $\mathrm{al}^{38}$ on the basis of the internal cracking tracked, the punching failure may occur by a localization of the strains in the CSC (thus the CSC being coincident with the failure crack) or by the development of a splitting crack (the CSC and the failure crack thus not being necessarily coincident). In the former case, a crack type $\mathrm{B}$ joining the edge of the column and a crack type $\mathrm{A}$ or $\mathrm{C}$ develop (see, e.g., PG20 in Figure 4). In the case failure occurs by development of a splitting crack, both the CSC (developing from the tension reinforcement up to a certain height) and a failure crack (developing with a flatter inclination, PE9 in Figure 4) can be observed ${ }^{38}$. In this latter case, the failure crack may develop from the shear band (crack type F, PG20, and PE9 in Figure 4) or may also develop within a region near to the supported area without the complete development of the shear band (crack type $\mathrm{F}^{\prime}, \mathrm{PF} 21$ in Figure 4).

\subsection{Discussion on the distribution of tangential cracks with flexural origin}

Another interesting aspect refers to the development of the tangential cracking in the vicinity of the column. Figure 5 shows for instance the radial strains (related to tangential cracking) on the top surface (tension side) of slabs PG-1 and PG-3 measured by Guandalini. ${ }^{44}$ The results clearly show that, as the level of load increases, the extent of the slab where tangential cracking occurs also increases. It is interesting to note that this region may extend beyond the location of the CSC, normally assumed to develop at a distance $d$ from the column edge. ${ }^{22,31,32}$ This fact is consistent with the observation that others cracks (type C) may potentially develop beyond the CSC for higher shear forces without merging with it (thus not governing the shape of the CSC).

\section{3 | Discussion on the kinematics of the CSC}

As previously introduced, Clément, ${ }^{32}$ Einpaul, ${ }^{39}$ and Einpaul et $\mathrm{al}^{38}$ measured the displacements of points inside of the slab using a robotic arm. Figure 6a shows the radial location of the center of rotation of the CSC calculated by Clément $^{32}$ at different load levels for test PF21. In addition, Figure $6 \mathrm{~b}$ plots the radial strains in the soffit of the slab as a function of the applied load. ${ }^{32}$ These results show that the radial location of the center of rotation of the CSC varies during loading. ${ }^{32}$ First, in the stage where the crack may be forming, the center of rotation is located near the axis of the column. As the load increases, the crack probably develops and the center of rotation shifts toward the edge of the column, but eventually moves back near failure. The results also show that when the center of rotation starts moving back, a reduction of the radial strains in the soffit of the slab is observed (refer to Figure 6b). As suggested by Clément, $^{32}$ this may indicate that both the movement of the center of rotation and the changes in the behavior of the 
(a)

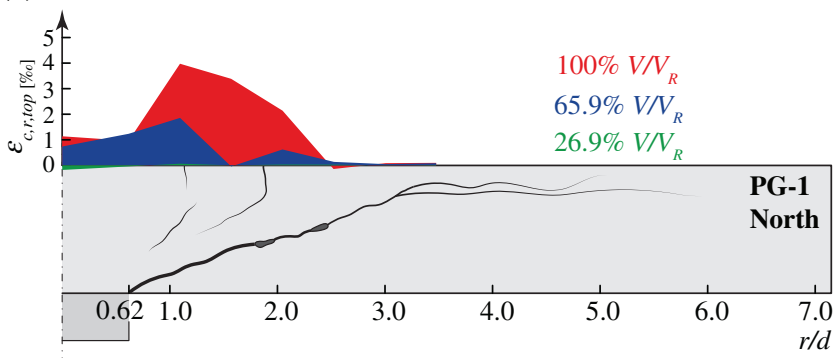

(b)

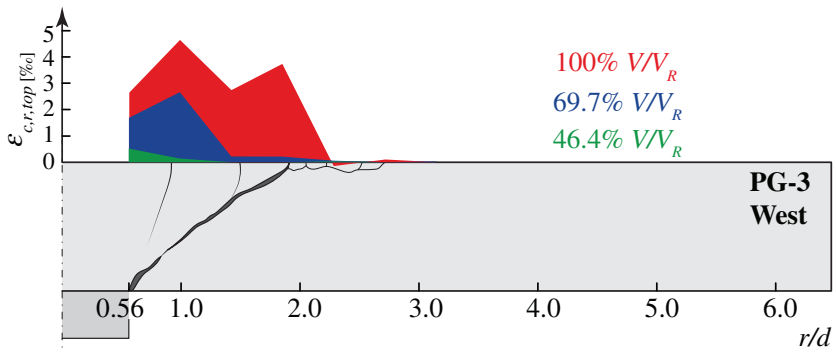

FIGURE 5 Experimental results of Guandalini ${ }^{44}$ : radial strains measured at the concrete top surface for specimens (a) PG1 $(B=3.0 \mathrm{~m} ; d=0.21 \mathrm{~m}$; $c=0.26 \mathrm{~m} ; \rho=1.5 \%$; measures performed along the east direction) and (b) PG3 ( $B=6.0 \mathrm{~m} ; d=0.456 \mathrm{~m}$; c $=0.52 \mathrm{~m} ; \rho=0.33 \%$; measures performed along the west direction); figure adapted from Guandalini ${ }^{44}$

concrete strains measured on the soffit of the slab are a result of the shear deformations occurring close to failure. This observation is also supported by other researchers ${ }^{20,39}$ that reach a similar conclusion relating the decompression of concrete strains observed in the soffit of the slab to the shear deformations occurring near failure.

With the help of several measuring points placed inside of the slab, Einpaul et $\mathrm{al}^{38}$ also identified the CSC and measured its crack width at an height $z / d \approx 0.8$. These results are presented in Figure 7 for six slabs with three different

(a) critical shear crack
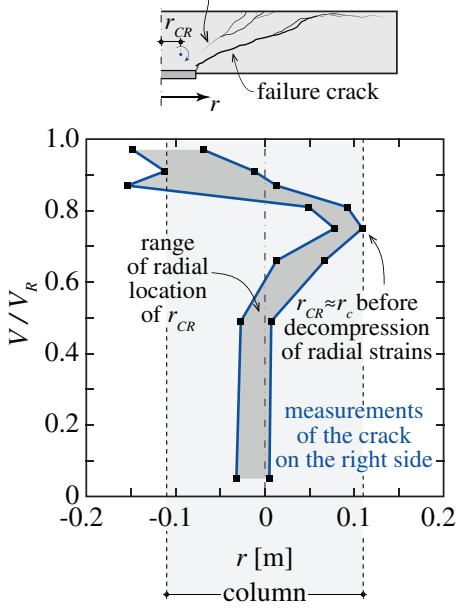

(b)
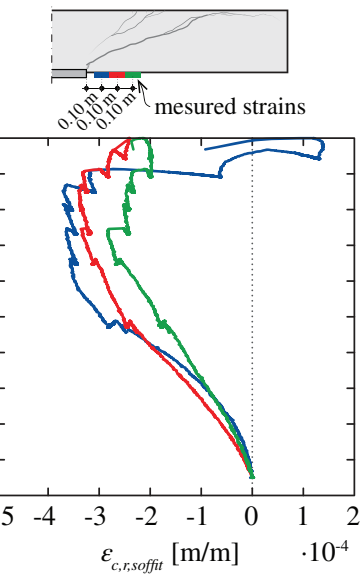

FIGURE 6 Results of Clément ${ }^{32}$ for slab PF21 $(B=3.0 \mathrm{~m} ; c=0.22 \mathrm{~m}$; $d=0.35 \mathrm{~m} ; \rho=0.75 \%$ ): (a) radial location of center of rotation (east-west axis); (b) concrete radial strains measured in the soffit of the slab; figure adapted from Clément ${ }^{32}$ columns sizes $\left(r_{c} / d \approx 0.4,0.8\right.$, and 1.6) and two different reinforcement ratios $(\rho \approx 0.75 \%$ and $1.50 \%)$. The results show that for a given level of rotation ${ }^{38}$ : (a) smaller crack widths are observed for larger column sizes (i.e., the crack width is a function of the number of cracks, with higher number of cracks for larger column sizes; refer to the average slope of Figure 7a-c); (b) for a given rotation, the crack width does not seem to be dependent on the flexural reinforcement ratio in the investigated range of cases (negligible differences between red and blue curves of Figure 7) but on the column size. Furthermore, Einpaul et $\mathrm{al}^{38}$ also observed that the relative displacement of the crack lips in the upper part of the CSC is approximately normal to the crack surface. Eventually, based on the measured displacements of points in the interior of the slab, Einpaul et $\mathrm{al}^{38}$ concluded that the center of rotation of the CSC in the tested specimens is inside the slab in terms of height.

\section{3 | MECHANICAL MODEL FOR PUNCHING SHEAR FAILURES}

\section{1 | Basis of the mechanical model}

Based on the previously discussed experimental findings, a comprehensive mechanical model is presented in this section describing the kinematics and load-transfer capacity of slabs failing in punching. The principles of the model are shown in Figure 8a and described in the following:

- Primary and secondary tangential cracks due to bending develop in the tension side of the slab after the analysis of the cracking development in section 2 . The primary tangential flexural cracks are assumed to develop within a radius $r_{\chi r}$ (measured from the axis of the column) where radial curvature is considered to be nonnegligible (in accordance with the results of Guanda$\operatorname{lini}^{44}$ and Guandalini et $\mathrm{al}^{49}$ ). The spacing of such cracks is assumed to be constant $\left(s_{f}\right)$.

- A CSC develops from the tension to the compression side (Figure 8) after Muttoni. ${ }^{22}$ According to Muttoni et al, ${ }^{30}$ this crack is assumed to be composed of an inclined tangential crack (cracks type $\mathrm{A}$ and $\mathrm{C}$ developing from the tension side) and a shear band (smeared crack type B developing on the compression side). The extent of each cracking type is considered to be a function of the associated displacement field. On the tension side, a mixedmode opening-sliding occurs (localized cracking), while on the theoretical compression side, deformations may localize in a shear band (smeared cracking, eventually followed by coalescence), see Figure $8 a^{30}$.

- The kinematics of the CSC accounts for two components. The first one refers to the rotation around the center of rotation due to flexural deformations (CR with coordinates $\left.\left(r_{C R}, z_{C R}\right)\right)$. The second one refers to the 

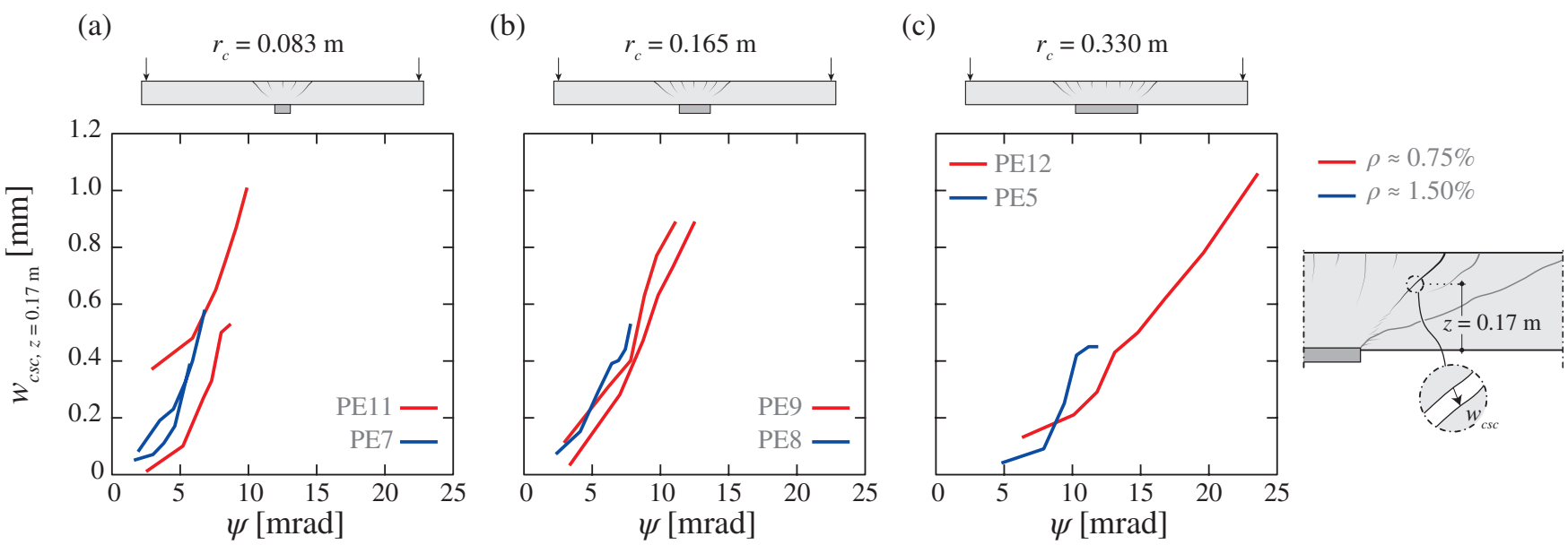

FIGURE 7 Experimental results of Einpaul ${ }^{39}$ and Einpaul et $\mathrm{al}^{38}$ : width of the critical shear crack as a function of the rotation of the slab for different column sizes and reinforcement ratios for six slender slabs $\left(B=3.0 \mathrm{~m} ; d=0.210-0.218 \mathrm{~m} ; f_{c}=36.7-44.1 \mathrm{MPa}\right)$; figure adapted from Einpaul ${ }^{39}$

(a)

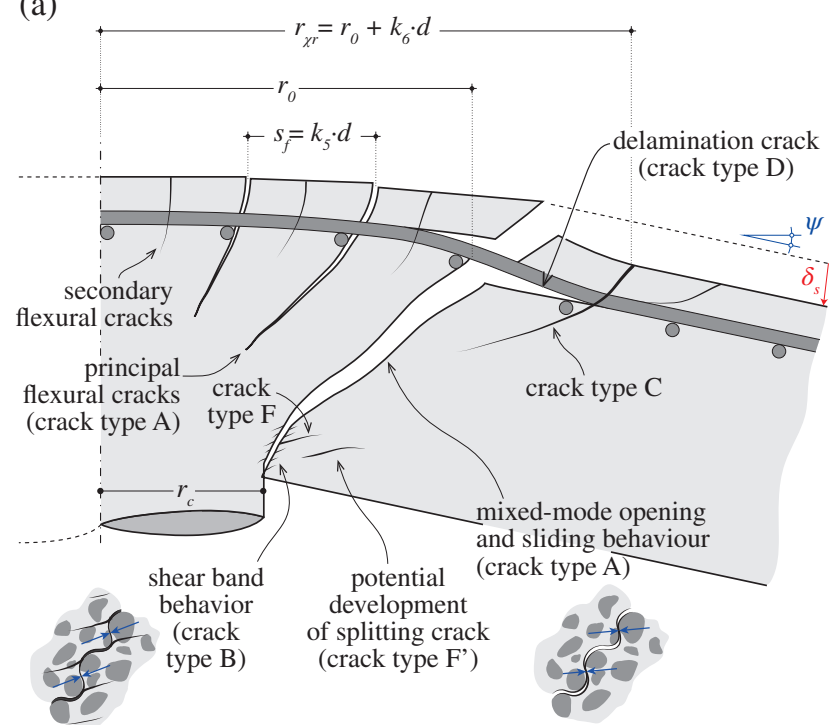

(b)

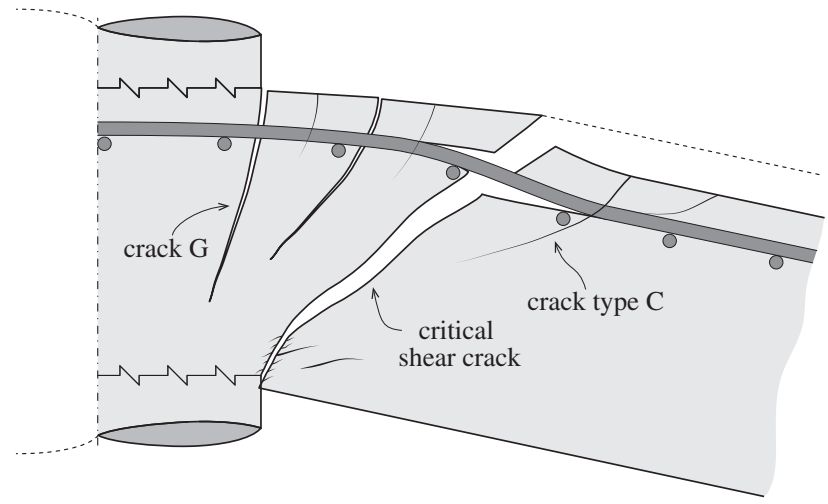

FIGURE 8 Punching shear of slab-column connection: (a) hypotheses of the mechanical model and description of potentially different phenomenological behaviors and cracking types; (b) case of column extending above the slab

shear deformation and consists of a constant displacement between both faces of the CSC. First, the behavior is governed by the flexural response (rotations) and, near failure, shear deformations develop. ${ }^{30}$ Such kinematics is consistent with the behavior experimentally observed by Clément ${ }^{32}$ (Figure 6) and to previous assumptions of the CSCT. ${ }^{30-32}$

- The location of the CSC at the level of the flexural reinforcement $\left(r_{0}\right)$ is considered to be variable, in agreement with the experimental observations on the radial deformations of Guandalini, ${ }^{44}$ see Figure 5.

As described by Einpaul et $\mathrm{al}^{38}$ and according to the experimental result observations, the failure may occur by a localization of the strains in the CSC (thus the CSC being coincident with the failure crack, Figure 8a) or by the development of a new splitting crack (also shown in Figure 8a and discussed by Einpaul et $\mathrm{al}^{38}$ ). For the latter case, the failure crack may propagate from the shear band (crack type $\mathrm{F}^{\prime}$ ) or at its vicinity (crack type $\mathrm{F}^{\prime}$ ), but in both cases, its development is assumed to be governed by the kinematics, shape, and stresses transferred by the CSC. Thus, despite the fact that the failure crack may not be coincident with the critical one, the punching strength is still governed by the properties and response of the $\operatorname{CSC}^{38}$ (as the splitting crack develops when the strength is attained in the shear band region). For all cases, thus, it is assumed that the punching strength can be calculated on the basis of the capacity of the CSC to transfer forces, by integration of the internal stresses developing along it based on the adopted kinematics and considering suitable fundamental laws for the shear-transfer actions.

It shall be noted that in the case of columns extending above the slab, see Figure $8 b$, the cracks develop mostly outside of the column region. However, the crack developing at the edge of the column (crack $\mathrm{G}$ in Figure $8 \mathrm{~b}$ ) concentrates a 
significant fraction of the rotation, which is related otherwise to the cracks type A developing inside the column region in the absence of an upper column. Consequently, the rotation concentrated at the CSC, governing the punching strength, is not significantly influenced by the presence of a column above the slab, as confirmed by examination and comparison of punching models to test results based on setups presenting both types of support conditions. ${ }^{22}$

\section{2 | Geometrical definition of regions of the slab with different behavior}

Following the experimental evidences discussed in section 2 and based on the hypotheses of the mechanical model established in section 3.1, different regions of the slab with distinct deformations have to be defined. As shown in Figure 9a, the mechanical model here presented considers that the slab is divided into three different portions: the inner and outer portions of the slab and a wedge-shaped region between them. Similarly to Kinunnen and Nylander's approach, ${ }^{15}$ it is considered that the inner portion of the slab deforms in a spherical manner (due to the development of principal and secondary flexural cracks) and that the outer portion of the slab behaves as a rigid body following a conical deformation (experimentally validated by several researchers (e.g., Reference 15,20,49)). The wedge-shaped region is considered as a deformable body (whose height is equal to the neutral axis depth) ensuring compatibility conditions associated with the rotations of the slab. This region accommodates the radial displacements due to bending, consistently to the approach of Kanellopoulos ${ }^{50}$ for beams. Above the neutral axis, the CSC separates the inner and outer portions of the slab while, below the neutral axis, the CSC separates the inner portion of the slab and the wedge element.

\subsection{Geometry of the CSC}

As discussed in Muttoni et $\mathrm{al}^{30}$ and Einpaul et al, ${ }^{38}$ as well as previously introduced based on the analysis of the cracking types (A or C compared to cracks type B in section 2), the CSC presents two regions with different phenomenological behaviors. The slope of the CSC is also typically different in these regions, with an often steeper inclination of the shear band (near to the supported area). This assumption is consistent with other experimental observations (Guandalini ${ }^{44}$ ) and theoretical approaches available in the scientific literature. ${ }^{12,24}$

In order to account for the varying slope of the CSC, a third-degree polynomial is used to characterize the geometry of the investigated CSC $(r(z))$ as

$$
r(z)=a_{0}+a_{1} \cdot z+a_{3} \cdot z^{3},
$$

where $a_{0}, a_{1}$, and $a_{3}$ are constants which can be calculated based on the following assumptions (Figure 9b):
1. The CSC develops between the edge of the column and the level of the flexural reinforcement, that is, $r(0)=r_{c}$.

2. The radial distance between the axis of column and the $\mathrm{CSC}$ at the level of the flexural reinforcement is equal to $r_{0}$, that is, $r(d)=r_{0}$.

3. The tangent to the CSC at the level of the flexural reinforcement passes through the center of rotation $\left(r_{C R}\right.$, $\left.z_{C R}\right)$ and is equal to $r^{\prime}(d)=1 / \tan (\beta(d))$, where $\beta(d)$ refers to the slope of the CSC at $z=d$. This assumption means that the displacement due to the rotation at the level of the flexural reinforcement has a direction normal to the crack lips (consistently with the experimental observations of Einpaul $\left.{ }^{39}\right)$.

Based on these assumptions, Equation (1) becomes:

$$
\begin{aligned}
r(z) & =r_{c}+\frac{3}{2} \cdot \frac{\left(r_{0}-r_{c}\right) \cdot z}{d}-\frac{z}{2 \cdot \tan (\beta(d))} \\
& +\frac{z^{3}}{2 \cdot d^{2} \cdot \tan (\beta(d))}-\frac{\left(r_{0}-r_{c}\right) \cdot z^{3}}{2 \cdot d^{3}},
\end{aligned}
$$

where $\tan (\beta(d))=\left(d-z_{C R}\right) /\left(r_{0}-r_{C R}\right) \geq 0.5$, the lower limit representing the minimal inclination of the CSC at $z=d$. It shall be noted that the punching shear resistance is not very sensitive to the function adopted for the CSC (reasonable variations of the shape of the CSC yielding similar results).

With respect to the location of the CSC at the level of the flexural reinforcement $\left(r_{0}\right)$, it has been discussed in section 2 that the region where tangential cracks develops progresses with the increase of the load level. In addition, it has also been shown that the potential development of cracks type $\mathrm{C}$ merging with cracks type A for higher load levels might govern the shape of the CSC. To account for this effect, the location of the CSC at the level of the flexural reinforcement is considered to vary between $r_{c}+0.75 d$ and $r_{c}+1.5 d$ (in agreement with the experimental observations in the saw-cuts of tested specimens) according to the following expression:

$$
\frac{r_{0}}{d}=\frac{V}{2 \cdot \pi \cdot d^{2} \cdot \tau_{l}} .
$$

This expression accounts for the parameter $\tau_{l}$ which refers to a reference value of the nominal shear stress causing flexural cracks to become inclined flexural-shear cracks and thus governing the shape of the CSC. The value of $\tau_{l}$ is assumed to be correlated to the shear strength of uncracked concrete (normally depending upon the square root of the compressive strength of concrete ${ }^{51}$ ) and accounting also for the size of the member. ${ }^{52}$ In addition, the value of $\tau_{l}$ is also considered to depend on the degree of utilization of the flexural reinforcement, in the sense that larger deformations lead to wider flexural cracks reducing the effective height of the section enabling the transmission of shear stresses and thus leading to stress concentrations. As a first estimate, the value of $\tau_{l}$ at failure is proposed to be calculated as 
(a)

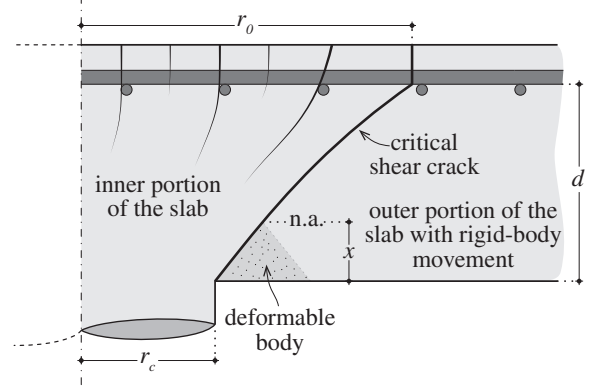

(c)

FIGURE 9 Definition of the geometry of the CSC: (a) definition of portions of the slab and description of adopted behaviors; (b) assumptions adopted to define geometry of CSC; (c) representation of range of $r(z)$ as a function of $r_{0}$ and corresponding potential locations of the $\mathrm{CR}$ for a given CSC; (d) values of $\tau_{l}$ calculated based on experimental results of Guandalini, ${ }^{44}$ Guidotti,${ }^{31}$ Tassinari, ${ }^{45}$ Fernández Ruiz et al., ${ }^{46}$ Clément, ${ }^{32}$ Lips,${ }^{47}$ Einpaul, ${ }^{39}$ and Drakatos $^{48}$ (b)

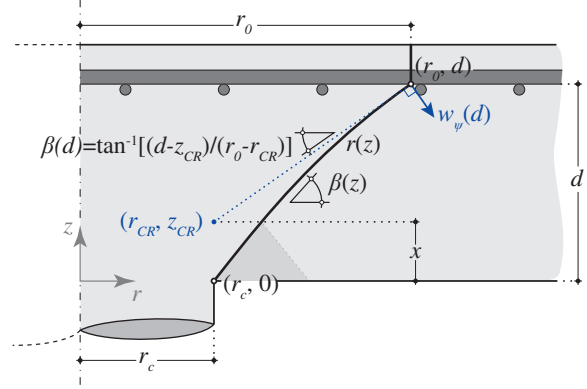

(d)

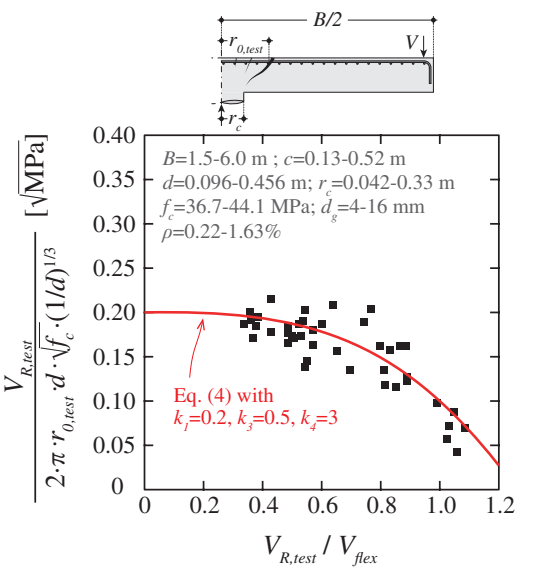

$$
\tau_{l}=k_{1} \cdot \sqrt{f_{c}} \cdot\left(\frac{k_{0}}{d}\right)^{k_{2}} \cdot\left[1-k_{3} \cdot\left(\frac{V_{R}}{V_{\text {flex }}}\right)^{k_{4}}\right],
$$

where $f_{c}$ refers to the concrete compressive strength (in $\mathrm{MPa}$ ); $V_{R}$ is the punching strength; $V_{\text {flex }}$ is the flexural strength; $d$ is the effective depth (in $\mathrm{m}$ ); $k_{0}$ is a constant reference size taken equal to $k_{0}=1.0 \mathrm{~m} ; k_{1}$ is constant value with unit $\left(\mathrm{MPa}^{1 / 2}\right)$ and $k_{2}-k_{4}$ are dimensionless constant values. With respect to the exponent governing size effect $\left(k_{2}\right)$, its value is taken as $1 / 3$ in agreement to Nielsen and Hoang $^{52}$ for phenomena governed by the tensile strength of concrete. A suitable value for the coefficient $k_{1}, k_{3}$, and $k_{4}$ can be derived by comparison to test results where information on the saw cuts can be observed. On the basis of available test data, ${ }^{31,32,39,44-48}$ it is proposed to consider $k_{1}=0.2, k_{3}=0.5$, and $k_{4}=3$ (refer to Figure 9d). The calculation of $\tau_{l}$ in this work is based on experimental values, but further work may be required in view of understanding the potential influence of other non-considered parameters. It can be noted that by calculating the value of $r_{0}$ as a function of a nominal reference value $\tau_{l}$, one considers that, for larger values of the applied shear stresses, the inclined flexure-shear cracks can develop at larger distances from the edge of the column and the value of $r_{0}$ becomes larger (in accordance with the results of Guandalini $^{44}$ ).

\section{4 | Kinematics and displacement field along the CSC}

According to the CSCT, the kinematics of the CSC at failure consists of two components (see Figure 10a):
1. a flexural deformation defined by a rotation $\psi_{c s c}$ around the center of rotation $\left(r_{C R}, z_{C R}\right)$,

2. a shear deformation characterized by a sliding $\delta_{s}$ with an angle $\gamma_{0}$ with respect to the steepest region of the CSC.

Hereafter, the following notations will be used (see Figure 10b):

- $w$ refers to a crack opening, that is, displacement normal to the face of the CSC,

- $\Delta$ is a displacement parallel to the face of the CSC,

- $\delta$ represents a vector sum of the displacements normal and parallel to the face of the CSC,

- $\gamma$ defines the angle between the face of the CSC and the displacements vector sum,

- $u$ and $v$ are respectively the radial and vertical components of $\delta$,

- $\alpha$ is the angle between the vertical axis and the displacement vector $\delta$.

This notation is used in combination with the subscripts: " $\psi$ " to describe the displacements associated with the rotation; " $s$ " referring to the components due to the shear deformation and " $T$ " when referring to the vector sum of both contributions of rotation and shear deformation.

\subsection{1 | Flexural deformations}

The displacement field along the CSC due to flexural deformations is a function of the location of the center of rotation $\left(r_{C R}, z_{C R}\right)$ and of the rotation developing in this crack $\left(\psi_{c s c}\right)$. 
(a)
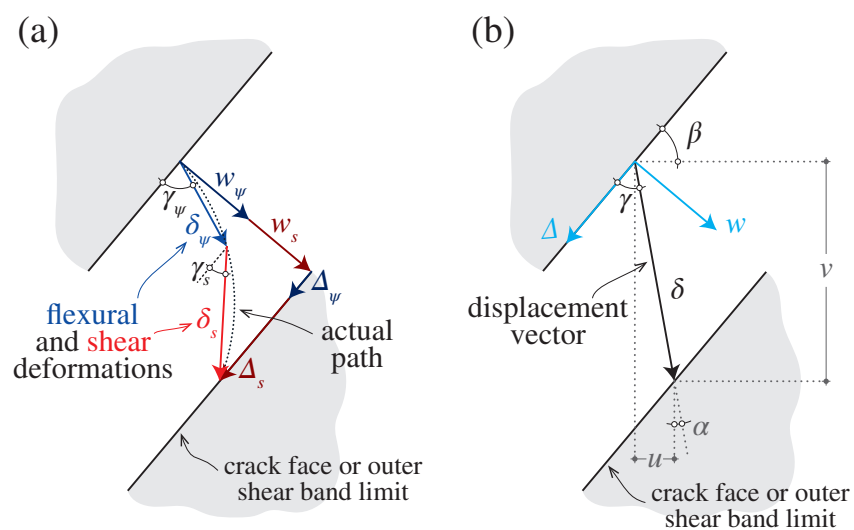

FIGURE 10 Definition of displacements: (a) flexural and shear deformations; (b) notation

Considering that the rotation of the slab $\psi$ is equally divided in the primary tangential flexural cracks without any contribution of the secondary flexural cracks, the rotation concentrated in the CSC $\psi_{c s c}$ can be calculated as follows as (similarly to Guidotti ${ }^{31}$ and in accordance with the experimental results of Clément ${ }^{22}$ and Einpaul et $\mathrm{al}^{38}$ ):

$$
\psi_{\mathrm{csc}}=\frac{\psi}{n_{c r}},
$$

where $n_{c r}$ represents the number of primary tangential flexural cracks, which can be calculated (similarly to Guidotti ${ }^{31}$ ) as

$$
n_{c r}=0.5+\frac{r_{\chi r}}{s_{f}},
$$

where $s_{f}$ refers to the distance between the primary flexural cracks and $r_{\chi r}$ is the extent of the region where these cracks develop (where the term 0.5 refers to the crack forming at the axis of symmetry), see Figure 8a. Scanty information has been reported regarding this spacing $\left(s_{f}\right)$ in punching tests. However, this parameter has been experimentally investigated for beams failing in shear (e.g., Cavagnis et $\mathrm{al}^{26}$ and Khaja and Sherwood ${ }^{53}$ ), where it has been shown that this value is mainly proportional to the effective depth $s_{f} \propto$ $k_{5} \cdot d$, with $k_{5}$ varying from 0.50 to 0.60 (e.g., Cavagnis et $\mathrm{al}^{26}$ and Khaja and Sherwood ${ }^{53}$ ). Consistently with these observations, a value $k_{5}=0.50$ will be adopted in this work. With respect to the distance $r_{\gamma r}$, it will be estimated as $r_{0}+k_{6} d$, where $k_{6}=0.25$ will be considered. This is physically consistent with the discussion of cracking observed in saw-cuts presented in section 2.1 (development of crack type $\mathrm{A}$ or $\mathrm{C}$ further away from the column that only merge at higher shear stresses) and with the experimental measurements of Guandalini ${ }^{44}$ presented in Figure 5.

With respect to the center of rotation associated with $\psi_{c s c}$ (Figure 9b), it is assumed that it is radially located at the edge of the column (in accordance to the experimental results of Clément ${ }^{32}$ before shear deformations take place, Figure 8$)$ and at the height of the neutral axis $\left(z_{C R}=x\right)$ associated with the tangential bending moment at $r_{0}$ (curvature calculated as $\chi=\psi / r_{0}$ corresponding to the assumption of a spherical deformed shape inside $r_{O}$ consistently with the works of Kinnunen and Nylander ${ }^{15}$ and others ${ }^{17-20}$ ). In this paper, the calculation of the height of the neutral axis is performed in a similar manner as Hallgren, ${ }^{20}$ that is, adopting an elastic-plastic behavior of concrete and reinforcement. The uniaxial behavior of concrete is considered to be characterized by the ascending branch given by the modulus of elasticity $\left(E_{c}\right.$; calculated based on the value of the uniaxial concrete compressive strength as Muttoni ${ }^{22}$ ) and by a plastic plateau at a stress of $\eta_{f c} \cdot f_{c}$ (where the factor $\eta_{f c}$ accounts for the brittleness of high-strength concrete and is calculated according to Muttoni ${ }^{54}$ as $\eta_{f c}=\left(30 / f_{c}\right)^{1 / 3} \leq 1$ with $f_{c}$ in $\mathrm{MPa})$. The elastic-plastic behavior of the reinforcement is also described by its modulus of elasticity $\left(E_{s}\right)$ and yield strength $\left(f_{y}\right)$.

Figure 9c shows the shape adopted for the CSC and the associated tangent inclination for a given $r_{O}$ and height of the neutral axis. Also, the range of potentially governing CSCs is shown in Figure 9c.

Finally, the displacement field along the CSC due to the rotation $\psi_{\mathrm{CSC}}$ can be calculated assuming that (Figure 11):

- above the neutral axis, all displacements localize in the CSC,

- below the neutral axis, only the vertical displacements (equal to the one at $z=z_{C R}$ ) localize at the CSC, while the wedge-shape region accommodates the radial displacements (in accordance to the approach of Kanellopoulos ${ }^{50}$ for beams in bending).

The radial $\left(u_{\psi}\right)$ and vertical $\left(v_{\psi}\right)$ components of the displacements resulting from the rotation $\psi_{c s c}$ around the CR localizing in the CSC are given by (see Figure 11b,c):

$$
\begin{gathered}
u_{\psi}(z)=\left\{\begin{array}{cc}
\psi_{\mathrm{csc}} \cdot\left(z-z_{C R}\right) & , \text { if } z \geq z_{C R} \\
0 & , \text { if } z<z_{C R},
\end{array}\right. \\
v_{\psi}(z)=\left\{\begin{array}{cc}
\psi_{\mathrm{csc}} \cdot\left(r_{C R}-r\right) & , \text { if } z \geq z_{C R} \\
\psi_{\mathrm{csc}} \cdot\left(r_{C R}-r_{z=z_{C R}}\right) & , \text { if } z<z_{C R} .
\end{array}\right.
\end{gathered}
$$

The vector of displacements due to the rotation localizing in the CSC can be computed as

$$
\delta_{\psi}(z)=\sqrt{u_{\psi}(z)^{2}+v_{\psi}(z)^{2}}
$$

and the angle between the vertical axis and this vector is given by

$$
\alpha_{\psi}(z)=\tan ^{-1}\left(-\frac{u_{\psi}}{v_{\psi}}\right) .
$$

The angle between the CSC and the vector of displacement due to the rotation is finally computed as

$$
\gamma_{\psi}(z)=\frac{\pi}{2}-\beta(z)+\alpha_{\psi}(z)
$$

and the corresponding displacements parallel $\Delta_{\psi}(z)$ and normal $w_{\psi}(z)$ to the CSC are calculated as follows (Figure 11) 


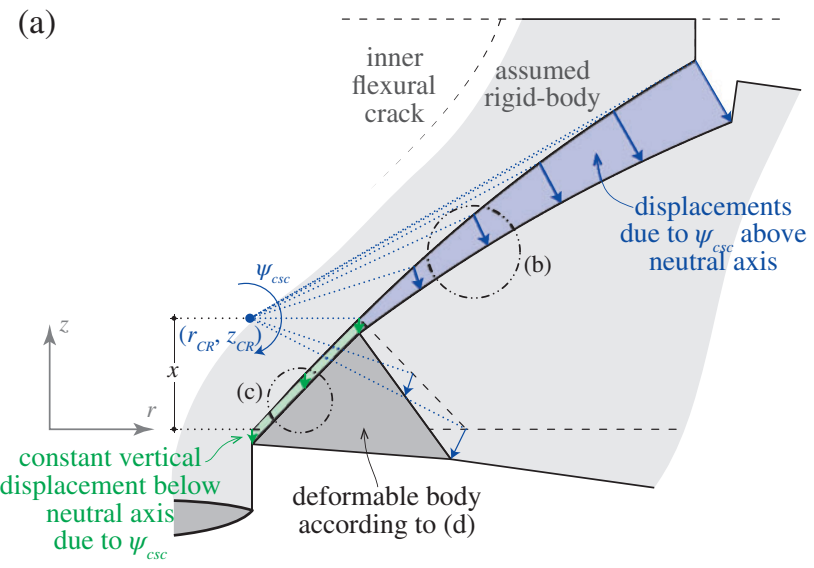

(c)

(b)

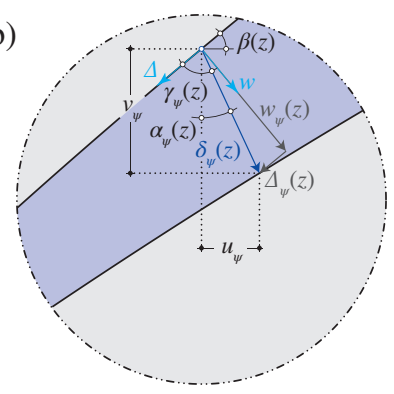

(d)
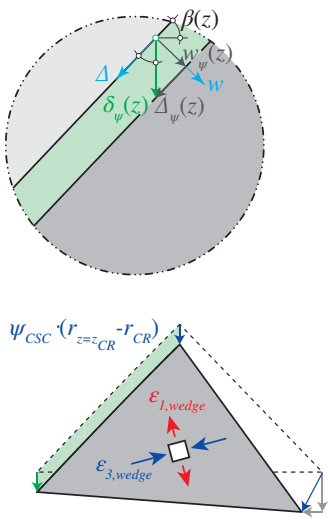

FIGURE 11 (a) Adopted kinematics and corresponding displacements along the critical shear crack due to rotation $\psi_{C S C}$; details of resulting displacement field in the (b) lower and (c) upper portion of CSC;

(d) wedge element and corresponding displacements associated with $\psi_{C S C}$

$$
\begin{aligned}
& w_{\psi}(z)=\delta_{\psi}(z) \cdot \sin \left(\gamma_{\psi}(z)\right), \\
& \Delta_{\psi}(z)=\delta_{\psi}(z) \cdot \cos \left(\gamma_{\psi}(z)\right) .
\end{aligned}
$$

\subsection{2 | Shear deformations}

Considering that the shear deformations fully localize at the $\mathrm{CSC}$, the resulting displacement field along it is characterized only by the total constant displacement $\delta_{s}$ (corresponding to a translation) and angle of sliding $\gamma_{s}(z)$ (variable due to the potentially variable tangent inclination of the CSC). With respect to the angle of sliding, it can be considered that the lowest angle measured between the CSC and the direction of the vector of shear deformations is related to the angle of dilatancy observed in push-off tests of concrete members (following the approach of Guidotti ${ }^{31}$ based on the results of Walraven ${ }^{55}$ ). As the point with steepest inclination along the failure surface is located at $z=0$ (edge of the column), the lowest angle of dilatancy occurs at this location and is equal to $\gamma_{s}(0)=\gamma_{0}$. Based on the analysis of experimental results and theoretical considerations, ${ }^{55-58}$ Clément $^{32}$ concluded that this angle should vary from $25^{\circ}$ to $30^{\circ}$. A value of $\gamma_{0}=27^{\circ}$ is adopted in this work (consistently with Guidotti, ${ }^{31}$ but limited to the value $90^{\circ}-\beta(0)$ corresponding to a vertical translation of the slab in the phase of shear deformations). Thereby, the angle between the CSC and the vector of shear deformations $\gamma_{s}(z)$ can be calculated as a function $\beta(z)$ as follows:

$$
\gamma_{s}(z)=\gamma_{0}+(\beta(0)-\beta(z))
$$

Considering a shear deformation (characterized by a constant displacement $\delta_{s}$ with an angle $\left.\gamma_{s}(z)\right)$, the corresponding displacements parallel $\Delta_{s}(z)$ and normal $w_{s}(z)$ to the CSC are computed as follows (Figure 12):

$$
\begin{gathered}
\Delta_{s}(z)=\delta_{s} \cdot \cos \left(\gamma_{s}(z)\right), \\
w_{s}(z)=\delta_{s} \cdot \sin \left(\gamma_{s}(z)\right) .
\end{gathered}
$$

Finally, the displacements parallel $\Delta_{T}(z)$ and normal $w_{T}(z)$ to the CSC associated with the combined effect of rotation and shear deformation are respectively given by

$$
\begin{aligned}
& \Delta_{T}(z)=\Delta_{\psi}(z)+\Delta_{s}(z), \\
& w_{T}(z)=w_{\psi}(z)+w_{s}(z),
\end{aligned}
$$

and its vector sum $\delta_{T}(z)$ and corresponding direction $\gamma_{T}(z)$ with respect to the CSC plan can be obtained as (Figure 12):

$$
\begin{gathered}
\delta_{T}(z)=\sqrt{w_{T}(z)^{2}+\Delta_{T}(z)^{2}}, \\
\gamma_{T}(z)=\tan ^{-1}\left(\frac{w_{T}(z)}{\Delta_{T}(z)}\right) .
\end{gathered}
$$

It should be noted that, following the development of the shear deformation, the CR moves away from the column edge (compare location of CR in Figures 11 and 12). This is in agreement with the results of Clement ${ }^{32}$ shown in Figure 6.

\section{5 | Internal stresses along the CSC}

As discussed by Muttoni et al, ${ }^{30}$ different phenomenological responses occur along the CSC. The zone in the tension side presents a mixed-mode opening-sliding response due to the development of a discrete crack (localizing strains, representing a localized cracking behavior) caused by flexural deformations. The zone in the compression side may in its turn behave as a shear band, where deformations smear in a narrow region (representing a smeared cracking behavior) eventually leading to coalesce in one single crack (see Figure 8). These two different phenomenological responses will be considered in this work by calculating the internal stresses along the CSC in accordance to the expected crack kinematics.

\subsection{1 | Transition between single crack behavior and shear band behavior}

The transition between these two distinct regimes (localized and smeared cracking) is a complex phenomenon and depends upon the opening and direction of the crack displacement vector, the loading path, and the concrete 
$202+70$

(a)

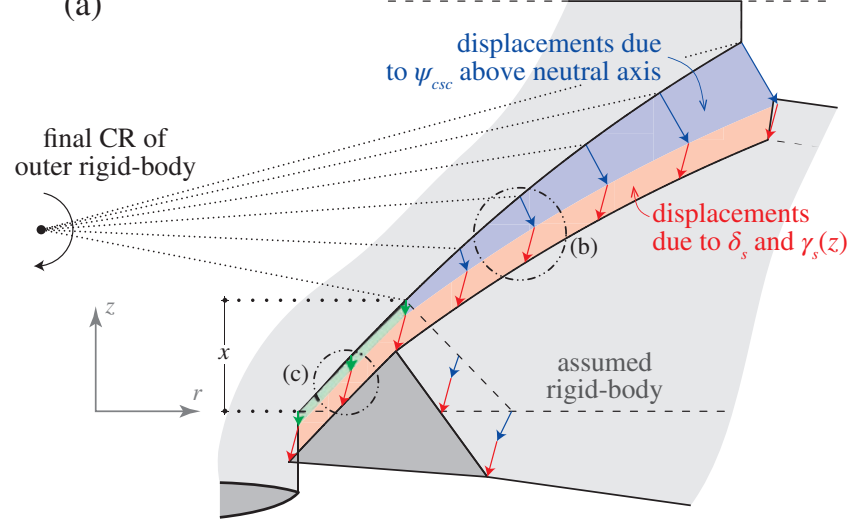

(b)

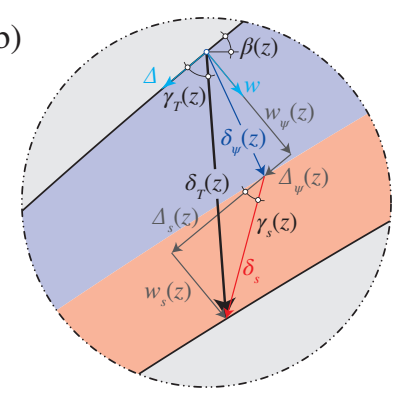

(c)

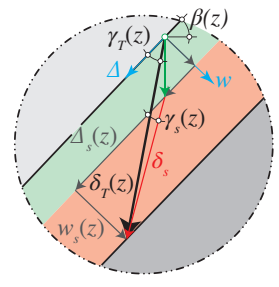

FIGURE 12 (a) Adopted kinematics and corresponding displacements along the critical shear crack due to combined effects of rotation $\psi_{C S C}$ and shear deformation $\delta_{s}$; details of resulting displacement field in the (b) lower and (c) upper portion of CSC

properties. ${ }^{43}$ With this respect, some interesting results have been reported by Jacobsen, ${ }^{43}$ who performed an experimental program with double-notched concrete specimens where an initial crack opening was applied (imposed displacement normal to the notched surface) followed by a shear displacement at a given angle (mixed-mode opening and sliding). Based on the experimental results, Jacobsen ${ }^{43}$ concluded that a clear localized cracking behavior (aggregate interlock along the notched surface) could only be obtained if: (a) a discrete crack caused by an initial opening displacement occurs (initial crack opening corresponding to a decrease on the normal stress of 30-50\% of the tensile strength) and (b) a shear displacement with an opening-to-sliding angle sufficiently large is applied (limit value of $40^{\circ}$ suggested by the author).

In this work, based on the experimental observations of Jacobsen, ${ }^{43}$ the transition between the localized and the smeared cracking regions will be defined on the basis of the initial crack opening $\left(w_{\psi}\right)$ and on the crack opening-to-crack sliding angles associated with flexural $\left(\gamma_{\psi}\right)$ and shear $\left(\gamma_{s}\right)$ deformations. The transition is thus defined according to the following criteria:

- The region of the CSC with $\gamma_{\psi} \leq 40^{\circ}$ will be assumed to have a smeared cracking response (Figure 13a).

- The response (localized or smeared cracking) of the region of the CSC with $\gamma_{\psi}>40^{\circ}$ is assumed to depend on the initial crack opening $\left(w_{\psi}\right)$ and on the crack opening-to-crack sliding angle associated with the shear displacement vector $\left(\gamma_{s}\right)$. In this case, the region of the CSC with $w_{\psi} \leq 0.5 w_{c}$ and $\gamma_{s} \leq 40^{\circ}$ is assumed to behave with a smeared cracking response as shown in Figure 13b (where $w_{c}$ is the crack opening corresponding to a zero tensile stress). On the contrary, localized cracking behavior is assumed to be governing in other cases $\left(\gamma_{\psi}>40^{\circ}\right.$ and $\gamma_{s}>40^{\circ}$, independently of $w_{\psi}$ as shown in Figure 13c; or $\gamma_{\psi}>40^{\circ}$ and $w_{\psi}>0.5 w_{c}$ independently of $\gamma_{s}$, corresponding to a full localization of the strains).

Mathematically, the vertical coordinate where the transition between both regimes occurs $\left(z_{t r}\right)$ can be expressed as follows:

$$
z_{t r}=\min \left(z_{\gamma_{s}=40^{\circ}} ; z_{w_{\psi}}=0.5 w_{c}\right) \geq z_{\gamma_{\psi}}=40^{\circ},
$$

where $z_{\gamma_{s}}=40^{\circ}$ refers to the vertical coordinate where $\gamma_{s}=40^{\circ}, z_{w_{\psi}}=0.5 w_{c}$ to the vertical coordinate where $w_{\psi}=0.5$ $w_{c}$ and $z_{\gamma_{\psi}}=40^{\circ}$ to the vertical coordinate where $\gamma_{\psi}=40^{\circ}$. It can be noted that in the previous condition it is assumed (consistently with the governing kinematics) that $\gamma_{s} \leq \gamma_{\psi}$.

\subsection{2 | Internal stresses developing in the segment with localized cracking}

In the region of the CSC where deformations localize in a single crack (opening-sliding mixed-mode behavior), it is considered that the shear-transfer capacity is governed by the residual tensile strength and the aggregate interlock stresses, leading to the following normal $\left(\sigma_{\text {agg }}\right)$ and shear $\left(\tau_{\text {agg }}\right)$ interlocking stresses as a function of the crack opening $\left(w_{T}\right)$ and sliding $\left(\Delta_{T}\right)$ (according to Cavagnis et $\mathrm{al}^{27}$ ):

$$
\begin{gathered}
\sigma_{a g g}\left(w_{T}, \Delta_{T}\right)=\sigma_{f c t}\left(w_{T}\right)+\sigma_{a g g, 0}\left(w_{T}, \Delta_{T}, f_{c}, d_{g}\right), \\
\tau_{a g g}\left(w_{T}, \Delta_{T}\right)=\tau_{a g g, 0}\left(w_{T}, \Delta_{T}, f_{c}, d_{g}\right),
\end{gathered}
$$

where $\sigma_{f c t}$ refers to the residual tensile strength, $\tau_{a g g, 0}$ and $\sigma_{a g g, 0}$ are the shear and normal stresses due to aggregate interlocking engagement. According to Hordijk ${ }^{59}$, the residual tensile strength can be calculated as

$$
\sigma_{f c t}=f_{c t} \cdot\left[1+\left(t_{1} \frac{w_{T}}{w_{c}}\right)^{3}\right] \cdot e^{\left(-t_{2} \frac{w_{T}}{w_{c}}\right)}-\frac{w_{T}}{w_{c}} \cdot\left(1+t_{1}{ }^{3}\right) \cdot e^{\left(-t_{2}\right)} \geq 0,
$$

where $f_{c t}$ refers to the tensile strength of concrete, $w_{c}$ is the crack opening corresponding to a zero tensile stress, and $t_{1}=3$ and $t_{2}=6.93$ are constants ${ }^{59}$. The tensile strength of concrete is computed according to the following relationships $\left(f_{c} \text { in } \mathrm{MPa}\right)^{27}$ :

$$
f_{c t}= \begin{cases}0.3 \cdot f_{c}^{2 / 3} & \text { for } f_{c} \leq f_{c 0, t} \\ 0.3 \cdot\left(f_{c 0, t} \cdot f_{c}\right)^{1 / 3} & \text { for } f_{c} \geq f_{c 0, t}\end{cases}
$$


(a)

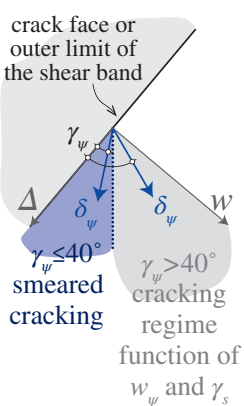

(b)

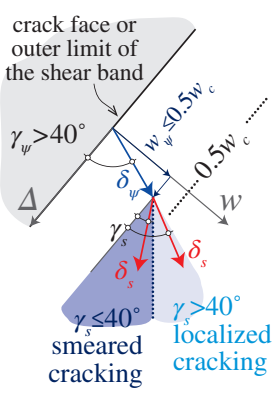

(c)

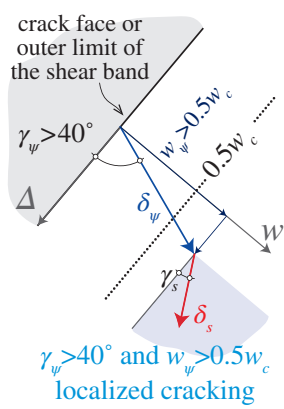

FIGURE 13 Adopted transition between localized and smeared cracking regimes function of the displacement field: (a) transition criterion based on the angle of the displacement vector associated with flexural deformations; (b) transition criterion based on the crack opening-to-crack sliding angle associated with shear deformations; (c) transition criterion based on the crack opening due to the flexural behavior

with $f_{c 0, t}=50 \mathrm{MPa}$ and the crack opening $w_{c}$ is computed as follows $\left(\right.$ Hordijk $\left.^{59}\right)$ :

$$
w_{c}=5.14 \cdot \frac{G_{F}}{f_{c t}},
$$

where the total fracture energy $G_{F}$ is calculated in accordance to the fib Model Code $2010^{60}$ :

$$
G_{F}=73 \cdot f_{c}^{0.18}, \quad\left(f_{c} \text { in } \mathrm{MPa}, G_{F} \text { in N/m }\right) .
$$

With respect to the aggregate interlock engagement stresses, the simplified formulation of Cavagnis et $\mathrm{al}^{27}$ will be used in this work $\left(f_{c}\right.$ in MPa):

$$
\begin{aligned}
& \sigma_{a g g, 0}=-c_{1} \cdot \sqrt{f_{c}} \cdot \frac{\bar{\Delta}^{7 / 3}}{\left(c_{3} \cdot \bar{w}\right)^{3+c_{3} \cdot \bar{\Delta}}}, \\
& \tau_{\text {agg }, 0}=c_{2} \cdot \sqrt{f_{c}} \cdot \frac{\bar{\Delta}^{4 / 3}}{\left(c_{3} \cdot \bar{w}\right)^{1.8+c_{3} \cdot \bar{\Delta}}},
\end{aligned}
$$

where $c_{1}=400$ (unit of $\sqrt{\mathrm{MPa}}$ ), $c_{2}=35$, (unit of $\sqrt{\mathrm{MPa}}$ ) and $c_{3}=40$ are constant values; $\bar{\Delta}=\Delta_{T} / d_{d g}$ and $\bar{w}=w_{T} / d_{d g}$ are the normalized displacements parallel and normal to the crack surface; $d_{d g}$ is the reference value of the crack roughness and is calculated according to Cavagnis et $\mathrm{al}^{27}$ as:

$$
d_{d g}=16+d_{g} \cdot \min \left(\left(\frac{60}{f_{c}}\right)^{2}, 1\right) \leq 40 \mathrm{~mm}
$$

with $d_{d g}$ and $d_{g}$ in mm and $f_{c}$ in MPa. According to Cavagnis et $\mathrm{al},{ }^{27}$ the reduction of $d_{g}$ for high concrete grades is related to a reduction of the roughness of the crack associated with the development of cracks trough the aggregates as described by Collins and Kuchma ${ }^{61}$. Cavagnis et $\mathrm{al}^{27}$ proposed also the consideration of an upper limit of $d_{d g}$ related to the limited increased of transferred stresses across a crack for higher aggregate sizes as experimentally observed by Sherwood et $\mathrm{al}^{62}$ for shear in beams (limit of
$40 \mathrm{~mm}$ in Equation (30)). It should be mentioned that Equations (28) and (29) have been proposed by Cavagnis et $\mathrm{al}^{27}$ based on the model of aggregate interlock of Walraven, ${ }^{58}$ but adopting the kinematics at failure of Guidotti $^{31}$ (defined by an initial crack opening and a sliding with a given angle with respect to the crack; see Guidotti ${ }^{31}$ for details). It is also important to note that other approaches could also be used to calculate the aggregate interlock engagement stresses (e.g., Guidotti ${ }^{31}$ and Walraven ${ }^{58}$ ) but the approach of Cavagnis et $\mathrm{al}^{27}$ is kept because of its simplicity and validation against the recent experimental results of Jacobsen. ${ }^{43}$

\subsection{3 | Internal stresses developing in the segment with smeared cracking}

A shear band behavior is considered for calculating the internal stresses in the region of the CSC where deformations are considered to develop in a band of finite thickness. The concept of shear band introduced by Jensen ${ }^{63}$ is used in this work to calculate the strains developing in a band where a given displacement field is assumed to occur. Figure 14a shows the typical cracking pattern observed locally near the column edge (refer also to Figure 8). A shear band with a width $\lambda$ together with a displacement field characterized by a total displacement $\delta_{T}(z)$ and a direction $\gamma_{T}(z)$ with respect to its axis (calculated in section 3.4) is shown in Figure 14b, where the principal strains result (Figure 14c, $\mathrm{d}^{63}$ ):

$$
\begin{aligned}
& \varepsilon_{1, s b}(z)=\frac{\delta_{T}(z)}{2 \cdot \lambda} \cdot\left(\sin \gamma_{T}(z)+1\right), \\
& \varepsilon_{3, s b}(z)=\frac{\delta_{T}(z)}{2 \cdot \lambda} \cdot\left(\sin \gamma_{T}(z)-1\right),
\end{aligned}
$$

where $\varepsilon_{1, s b}$ and $\varepsilon_{3, s b}$ refer to the principal tensile and compressive strains, respectively, in the shear band. The principal direction of compression with respect to the shear band axis is given by (refer to Figure 14c,d):

$$
\theta_{s b}(z)=\frac{\pi}{4}-\frac{\gamma_{T}(z)}{2} .
$$

The width of the band $\lambda$ will be considered to be related to the size of the aggregate $\left(\lambda=d_{d g}\right)$. This simplification is consistent with other approaches, based on the concept of localization on a crack band (e.g., Reference 64) and supported on the following considerations: (a) the width of the band is considered to have a finite size even in the case of a zero aggregate size $(\lambda=16 \mathrm{~mm})$ and $(b)$ the influence of the aggregate size on the width of the band decreases in the case of high-strength concrete due to cracking through the aggregates ${ }^{29,61,65,66}$ (thus reducing the influence of this parameter on the width of the shear band).

In order to determine the associated state of stresses (Figure 14g), a strain-stress relationship adapted from the work of Guidotti et $\mathrm{al}^{67}$ will be used in this work (refer to 
Appendix). The formulae presented by Guidotti et $\mathrm{al}^{67}$ allows determining the axial stress $\left(\sigma_{3}\right)$ and the radial strains $\left(\varepsilon_{1}\right)$ of a concrete cylinder as a function of the axial strain $\left(\varepsilon_{3}\right)$ and confining pressure.

The original formulation of Guidotti et $\mathrm{al}^{67}$ is nevertheless valid for concrete cylinders, whereas the state of strains in the investigated axisymmetric element (Figure 14e) is more complex (in most cases two compressive and one tensile strains, Figure 14f ). In fact, in addition to the principal tensile and compressive strains (developing in a radial plane), also a state of tangential strains $\left(\varepsilon_{2, s b}\right)$ in the shear band results from the flexural deformations in the inner portion of the slab (inside $r_{0}$ ) and from the radial displacement field occurring in the shear band. The former component induces a constant state of tangential strains in the band, whereas the latter leads do a discontinuity of tangential strains along its thickness (Reference 63; see Figure 14c).

When analyzing the behavior of a concrete panel representing an element of shear band (Figure $14 \mathrm{f}-\mathrm{g}$ ), two distinct effects have thus to be distinguished: (a) the favorable effect of a potential tangential compression $\left(\varepsilon_{2, s b}\right)$ on the peak stress and deformation capacity of the $\varepsilon_{3}-\sigma_{3}$ relationship (biaxial compression) and (b) the potential unfavorable influence of imposed tensile strains $\left(\varepsilon_{1, s b}\right)$ on the $\varepsilon_{3}-\sigma_{3}$ relationship (strain softening). In the following, these phenomena are briefly presented as well as their consideration in the constitutive law adopted for concrete in this region.

\section{Influence of compressive tangential strain}

As schematically represented in Figure 15a, the behavior of a panel in biaxial compression is actually in between the behavior of an unconfined and confined concrete element. ${ }^{68,69}$ The behavior of concrete panels under biaxial compression has been investigated by numerous researchers (e.g., Kupfer et $\mathrm{al}^{68}$ and Kupfer and Gerstle ${ }^{69}$ ). The original experimental research presented by Kupfer et al. ${ }^{68}$ showed that concrete compressive strength and deformation capacity increase in the case of biaxial compression. On that basis, Kupfer and Gerstle $^{69}$ proposed an envelope in the stress space for concrete panels under biaxial loading conditions. Furthermore, Kupfer et $\mathrm{al}^{68}$ have also shown that the increased peak stress in the case of biaxial compression may increase up to approximately $20 \%$ of the uniaxial compression strength.

In this work, the favorable effect of biaxial compression due to tangential compressive strains developing in the region with smeared cracking will be accounted for in a simplified manner. This will be performed by considering that the strain-stress relationship of the region with smeared cracking corresponds to the one of a cylinder with a confining pressure leading to a peak stress of $\kappa_{b} \cdot f_{c}$. As previously discussed, the value of $\kappa_{b}$, representing the enhancement of the peak strength and deformation capacity of concrete (see differences between black and blue curves in Figure 15a,c), may have values between 1 and approximately 1.2 (a)
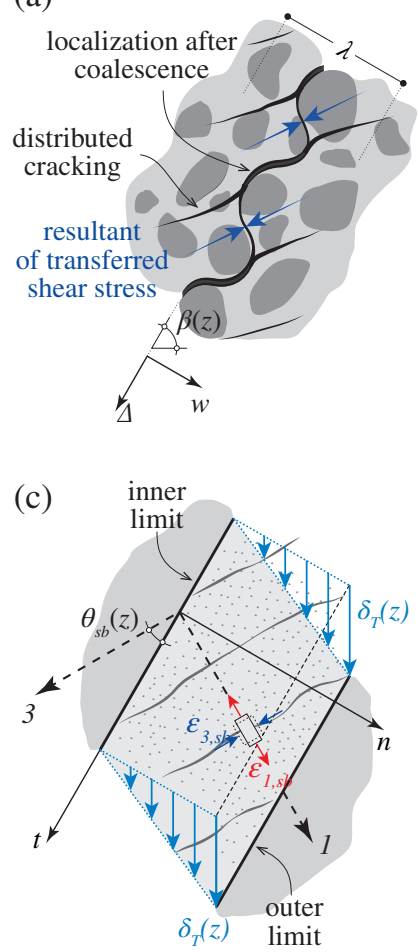

(e)

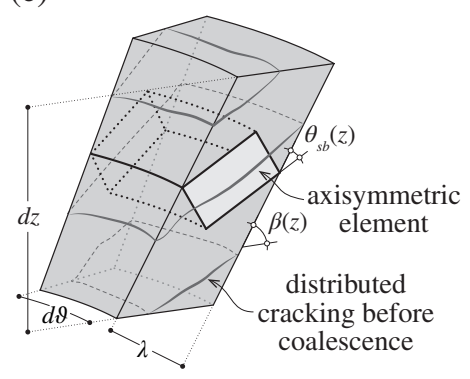

(b)

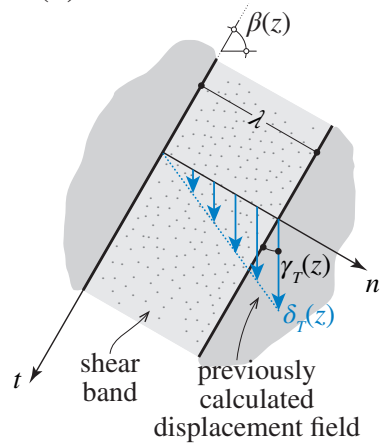

(d)

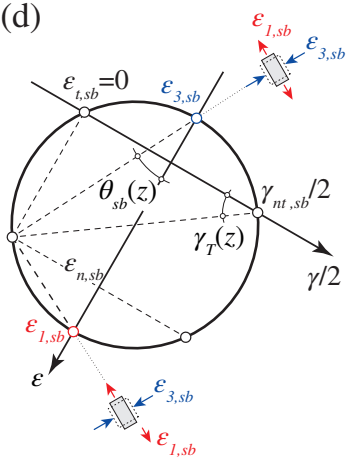

(f)

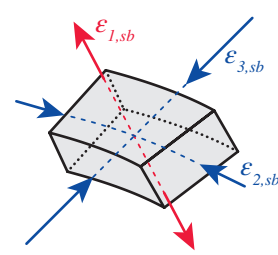

(g)

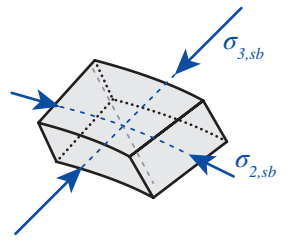

FIGURE 14 Model assuming the formation of a shear band: (a) cracking; (b) geometrical definition and relative radial displacement field; (c) strains field; (d) Mohr's circle; (e) axisymmetric view of the shear band; (f) strain and $(\mathrm{g})$ stress state of an element of the shear band

depending on the level of transverse compression. ${ }^{68}$ In this work, a constant value of $\kappa_{b}=1.1$ is considered, representing the case where moderate values of the tangential compression develop in the region with smeared cracking (in agreement with the results of the mechanical model).

\section{Influence of imposed tensile transverse radial strain $\varepsilon_{1}$}

When investigating the shear strength of reinforced concrete panels, Vecchio and Collins ${ }^{51}$ identified a decrease of the concrete compressive strength (compression softening) in the presence of transverse tensile strains. Consistently to these observations, Muttoni ${ }^{54}$ suggested that, for the case of unreinforced concrete members, the influence of imposed transverse tensile strains can be investigated on the basis of the $\varepsilon_{1}-\sigma_{3}$ relationship (as for instance done by Guidotti et $\mathrm{al}^{67}$ ). This approach is represented in Figure 15a, where $f_{c, \text { eff }}$ corresponds 
(a)

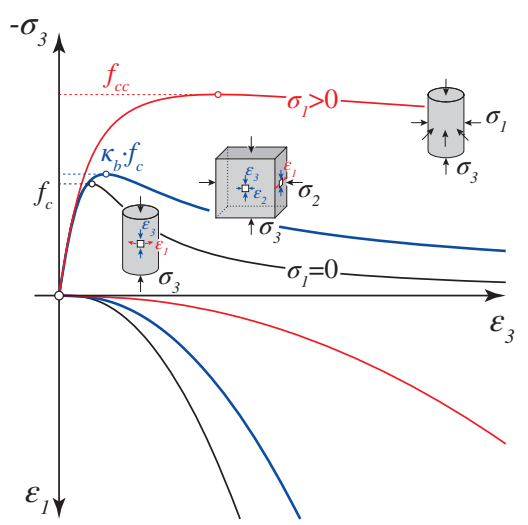

(b)

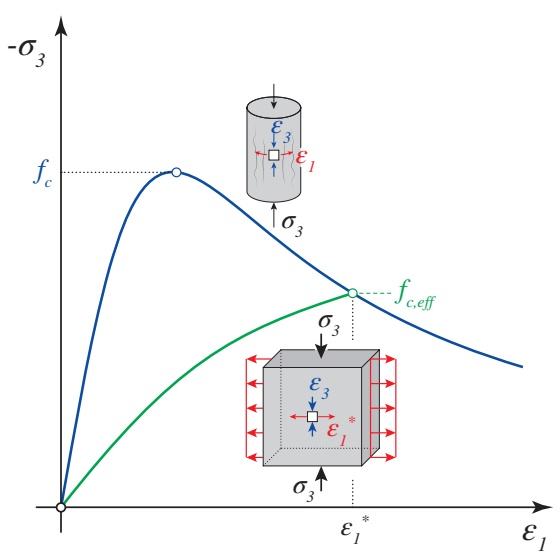

(c)

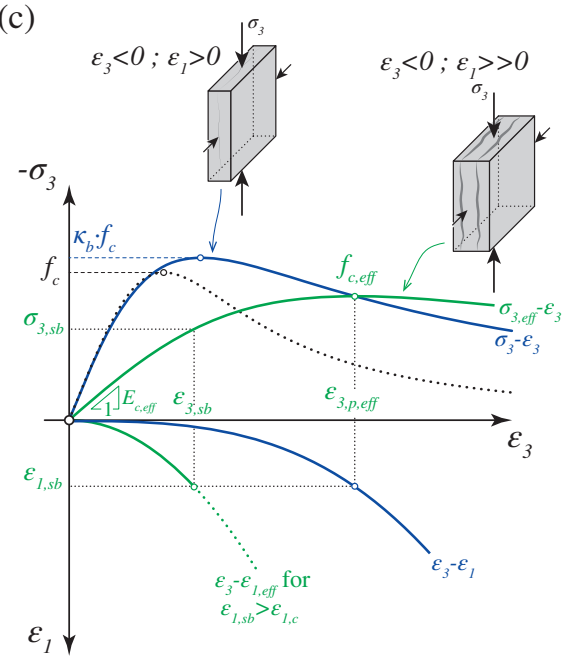

FIGURE 15 Adopted behavior of concrete in the shear band: (a) influence of confining pressure $\left(\sigma_{1}\right)$ on the compression resistance $\left(\sigma_{3}\right)$ and deformation capacity ( $\varepsilon_{1}$ and $\varepsilon_{3}$ ) of different concrete elements (based on References 67,68); (b) reduction of concrete compressive strength due to imposed transverse strain (adapted from Muttoni ${ }^{54}$ ); (c) procedure to calculate the stresses developing in the shear band

to the value of $\sigma_{3}$ associated with the imposed transverse tensile strain $\varepsilon_{1}{ }^{*}$. In addition, a softer strain-stress relationship (green line in Figure 15b) accounting for the presence of large tensile strains can thus be derived considering that its peak occurs at the point with coordinates $\left(\varepsilon_{1}{ }^{*}, f_{c, e f f}\right)$.

\section{Calculation of normal and shear stresses in the region of smeared cracking}

The stresses acting in the axisymmetric element of shear band can be calculated accounting for the potential effects of biaxial compression and imposed transverse tensile strains based on the principles described above. The procedure followed to calculate the stress $\sigma_{3, s b}$ in the shear band is shown in Figure $15 \mathrm{c}$, where both $\varepsilon_{3}-\sigma_{3}$ and $\varepsilon_{3}-\varepsilon_{1}$ relationships are plotted for concretes under different conditions. The dotted black curve represents the behavior of an unconfined concrete cylinder. The blue curves $\varepsilon_{3}-\sigma_{3}$ and $\varepsilon_{3}-\varepsilon_{1}$ represent the behavior of a concrete cylinder with a confining pressure leading to a peak strength equal to $\kappa_{b} \cdot f_{c}$. The difference between the black dotted and blue curves represents the considered beneficial effect of biaxial compression on the concrete behavior. However, the behavior of the concrete in the shear band is still not represented by the blue curves in Figure 15c, as they do not consider the imposed tensile strain $\varepsilon_{1, s b}$. To account for it, a softer $\varepsilon_{3}-\sigma_{3 \text {,eff }}$ relationship (green curve in Figure 15c) is derived considering that its peak occurs at the stress $f_{c \text {, eff }}$ corresponding to the imposed transverse tensile strain $\varepsilon_{1, s b}$ (by introducing $\varepsilon_{1, s b}$ in the blue curve $\varepsilon_{3}-\varepsilon_{1}$ and calculating the corresponding $\sigma_{3}$, consistently with the procedure pro-

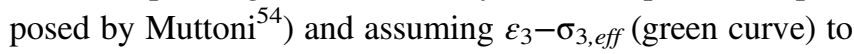
be an homothetic curve of $\varepsilon_{3}-\sigma_{3}$ (blue curve). Finally, the stress $\sigma_{3, s b}$ in the shear band can be computed by introducing $\varepsilon_{3, s b}$ in the green curve $\varepsilon_{3}-\sigma_{3, \text { eff. }}$
By considering the $\varepsilon_{3}-\sigma_{3}$ relationship proposed by Guidotti et $\mathrm{al}^{67}$ and a simplified $\varepsilon_{1}-\varepsilon_{3}$ relationship, the previously described steps can be analytically solved, leading to the following expression to calculate the principal compressive stress in the smeared cracking region (see Appendix for detailed analytical derivation):

$$
\sigma_{3, s b}=(\bar{\alpha}-1) \cdot \frac{\varepsilon_{3, s b} \cdot E_{c, e f f}}{\bar{\alpha}-1+\left(\frac{\varepsilon_{3, s b}}{\varepsilon_{3, p, e f f}}\right)^{\bar{\alpha}}},
$$

where $\bar{\alpha}$ is a factor of the $\varepsilon_{3}-\sigma_{3}$ relationship accounting for the brittleness of concrete (Equation (A6)) ${ }^{67} ; E_{c, \text { eff }}$ is the effective modulus of elasticity of the concrete, whose value is a function of the imposed transverse tensile strain in the shear band $\varepsilon_{1, s b}$ (Equation (A10) derived in the Appendix); $\varepsilon_{3, p \text {,eff }}$ is the strain at the peak of the $\varepsilon_{3}-\sigma_{3, \text { eff }}$ relationship, whose value is also a function of the imposed transverse tensile strain in the shear band $\varepsilon_{1, s b}$ (Equation (A9)).

Figure 16 shows the $\varepsilon_{3}-\sigma_{3, s b}$ according to Equation (34) obtained for different values of the imposed transverse tensile strain $\left(\varepsilon_{1, s b}\right.$. $)$ adopting two different concrete compressive strengths. This figure clearly shows the effects of brittleness and strain softening (due to imposed transverse tensile strains).

Still with respect to the calculation of the stress state in the shear band, it will additionally be assumed that the principal directions of stresses are parallel to the principal directions of deformations $\theta_{s b}(z)^{70}$ and that the stress in the principal tensile direction is equal to $\sigma_{1, s b}=0$. In these conditions, the normal and shear stresses parallel to the axis of the shear band can be respectively calculated as

$$
\begin{gathered}
\sigma_{s b}(z)=\sigma_{3, s b}(z) \cdot \sin \left(\theta_{s b}(z)\right)^{2}, \\
\tau_{s b}(z)=-\sigma_{3, s b}(z) \cdot \sin \left(\theta_{s b}(z)\right) \cdot \cos \left(\theta_{s b}(z)\right) .
\end{gathered}
$$




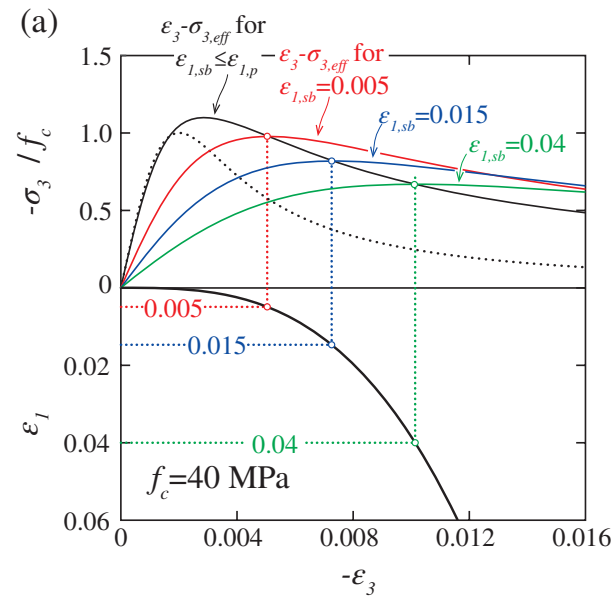

FIGURE 16 Calculated $\varepsilon_{3}-\sigma_{3, s b}$ relationships as a function of the imposed transverse tensile strain in the shear band $\varepsilon_{1, s b}$ for two concrete compressive strengths: (a) $f_{c}=40 \mathrm{MPa}$ and (b) $f_{c}=80 \mathrm{MPa}$

\subsubsection{Contribution of dowel action}

As shown in Figure 17a, dowelling of flexural reinforcement bars may potentially develop at failure contributing to the shear strength (e.g., Rasmussen, ${ }^{71}$ Krefeld and Thurston, ${ }^{40}$ Millard and Johnson, ${ }^{72}$ Fernández Ruiz et al, ${ }^{28,41,42}$ Campana et al, $^{36}$ Einpaul $\left.^{39}\right)$. In this work, a similar approach to that followed by Einpaul ${ }^{39}$ is considered, consisting on a combination of the approaches of Millard and Johnson ${ }^{72}$ (yield criterion), Fernández Ruiz et $\mathrm{al}^{28,41}$ (reduced capacity of spalled concrete to carry tensile stresses), Cavagnis et $\mathrm{al}^{27}$ (expression to calculate the spalled concrete tensile stresses) and Randl $^{73}$ (activation of the dowel action) as explained in the following.

According to Fernández Ruiz et $\mathrm{al}^{28}$ the ability of a dowelled bar to transfer shear forces when spalling of the concrete cover is governing can be investigated based on the equilibrium of the dowelling forces of the bar with the surrounding concrete tensile stresses (Figure 17b). The stresses in the concrete can be evaluated assuming a reduced tensile strength developing in a given area (length $L_{d a}$, width $\left.b_{e f f}\right){ }^{28}$ The vertical and moment equilibrium conditions of the free body (previously adopted by, e.g., Reference 39) shown in Figure 17c allows thus for calculating the acting shear force $\left(V_{d a, b a r}\right)$ as a function of the acting moment $\left(M_{d a, b a r}\right)$ :

$\left\{\begin{array}{l}V_{d a, b a r}=\sigma_{t} \cdot b_{e f f} \cdot L_{d a} \\ M_{d a, b a r}=V_{d a, b a r} \cdot \frac{L_{d a}}{2}\end{array} \Rightarrow V_{d a, b a r}=\sqrt{2 \cdot \sigma_{t} \cdot b_{e f f} \cdot M_{d a, b a r}}\right.$,

where the effective width of spalled concrete $b_{\text {eff }}$ can be calculated as Fernández Ruiz et $\mathrm{al}^{41}$ :

$$
b_{e f f}=s_{b}-\phi \leq \min (4 \cdot c ; 6 \cdot \phi),
$$

whose parameter $s_{b}$ refers to the bar spacing, $\phi$ to the bar diameter and $c$ to the concrete cover. The maximum capacity of the bar to carry a moment $(M)$ in the presence of normal forces $(N)$ is nevertheless limited by the yield conditions of the bar and can be approximated by the following yield criterion (bar with an equivalent square section $)^{72,74}$ :

$$
\frac{M}{M_{p}}+\left(\frac{N}{N_{p}}\right)^{2}=1 \Rightarrow M=M_{p} \cdot\left(1-\left(\frac{N}{N_{p}}\right)^{2}\right),
$$

where $N_{p}$ and $M_{p}$ are the plastic normal force $\left(N_{p}=\right.$ $\left.\pi \phi^{2} / 4 \cdot f_{y}\right)$ and plastic moment $\left(M_{p}=\phi^{3} / 6 \cdot f_{y}\right)$. By combining Equations (37) and (39) $\left(M_{d a, b a r}=M\right)$, the maximum available dowelling contribution of one bar can eventually be calculated as (similar equations have been previously derived or proposed by other researchers as e.g., Rasmussen, ${ }^{71}$ Millard and Johnson, ${ }^{72}$ Randl, $^{73}$ and Einpaul $^{39}$ ):

$$
V_{d a, \text { max }, \text { a } a r}=\sqrt{\frac{1}{3}} \cdot \sqrt{\phi^{3} \cdot b_{e f f}} \cdot \sqrt{\sigma_{t} \cdot f_{y} \cdot\left(1-\left(\frac{\sigma_{s}}{f_{y}}\right)^{2}\right)},
$$

(a)

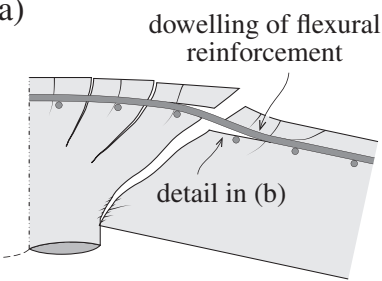

(c)

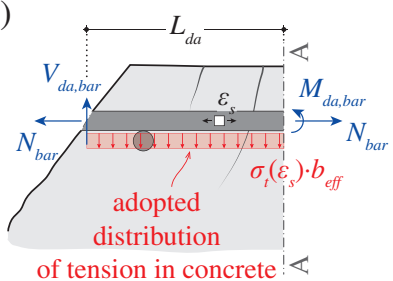

(b)

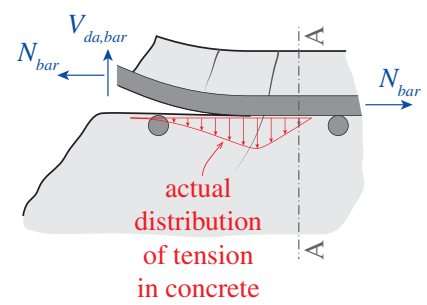

(d)

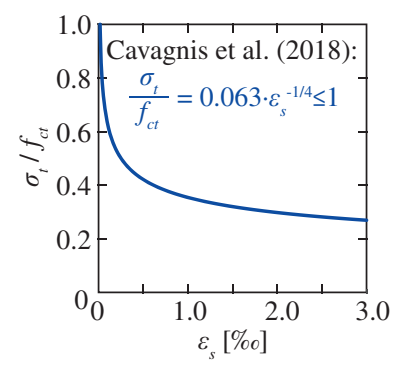

FIGURE 17 Calculation of shear transfer contribution due to dowelling of flexural reinforcement: (a) investigated phenomenon; (b) localized deformation of the bar and associated distribution of tensile stresses in the spalled concrete; (c) representation of the equilibrium of local free-body of the bar and surrounding concrete according to Einpaul ${ }^{39}$; (d) reduction of tensile stresses in the bar as a function of the state of strains in bar according to Cavagnis et $\mathrm{al}^{27}$ 
where the normal force in the bar is replaced by $N=\pi \phi^{2} / 4 \sigma_{s}$, with $\sigma_{s}$ representing the stress in the flexural reinforcement considering only the effect of the rotation $\psi$ based on the previously introduced assumption of a spherical deformation inside $r_{0}$, that is, shear deformation not affecting the strain and stress of the flexural reinforcement:

$$
\sigma_{s}=\varepsilon_{s} \cdot E_{s}=\frac{\psi \cdot\left(d-z_{C R}\right)}{r_{0}} \cdot E_{s} \leq f_{y}
$$

With respect to the tensile capacity of the concrete cover (spalling strength), it shall be noted that the tensile strains in the reinforcement reduce the ability of the spalled concrete to carry tensile stresses. ${ }^{41}$ Based on the works of Fernández Ruiz et $\mathrm{al}^{28,41}$ Cavagnis et $\mathrm{al}^{27}$ proposed the following expression to calculate the tensile stresses in the spalled concrete as a function of the state of strains in the flexural reinforcement (Figure 17d):

$$
\frac{\sigma_{t}}{f_{c t}}=0.063 \cdot \varepsilon_{s}^{-1 / 4} \leq 1
$$

where the strains in the flexural reinforcement $\varepsilon_{s}$ are computed in accordance to Equation (41). According to Randl, ${ }^{73}$ the contribution of dowel action of a bar $\left(V_{d a, b a r}\right)$ can be calculated as a function of the slip following a parabolic function as follows:

$$
V_{d a, b a r}=V_{d a, \max , b a r} \cdot \min \left(\sqrt{\frac{s}{s_{\max }}}, 1\right),
$$

where $s_{\max }$ refers to the slip required to activate the maximum dowel contribution, which can be assumed as $0.10 \phi$ to $0.20 \phi^{73}$ (a value of $0.20 \phi$ is adopted in this work). The slip of the bar refers to the vertical projection of the vector sum of flexural and shear deformations at the level of the flexural reinforcement, which can be calculated on the basis of the adopted kinematics as

$$
s=\left(r_{0}-r_{C R}\right) \cdot \psi_{\mathrm{csc}}+\delta_{s} \cdot \cos \left(\frac{\pi}{2}-\beta(0)-\gamma_{0}\right) .
$$

The contribution of dowel action of the flexural reinforcement to the punching shear strength can finally be calculated by multiplying the contribution of one bar by the number of bars intersected by the CSC $\left(n_{b}=2 \pi r_{0} / s_{b}\right.$ with the bar spacing given by $s_{b}=\pi \phi^{2} /(4 d \rho)$ considering one layer of flexural reinforcement in each direction $)^{28,39,42}$ :

$$
V_{D A}=n_{b} \cdot V_{d a, b a r}=8 \cdot \frac{r_{0} \cdot d}{\phi^{2}} \cdot \rho \cdot V_{d a, b a r}
$$

With respect to dowelling action of the compression reinforcement, this effect is neglected in this work.

\section{6 | Calculation of the punching shear strength}

The punching strength can be calculated in a similar manner as performed in the $\mathrm{CSCT}^{22}$ (Figure 1b), by intersecting a failure criterion (providing the shear strength for a given opening of the CSC) with a load-deformation relationship (providing the rotations and associated crack openings for a given level of applied load).

The load-rotation relationship can be calculated as described by Muttoni $^{22}$ using a quadri-linear momentcurvature relationship. The failure criterion is obtained by numerical integration of the internal stresses (calculated in section 3.5) along the CSC (whose geometry was defined in section 3.2) as follows:

$$
\begin{aligned}
& V_{c}\left(\psi, \delta_{s}\right)=\overbrace{2 \cdot \pi \cdot \int_{0}^{z_{t r}} \frac{r(z)}{\sin (\beta(z))} \cdot\left[\tau_{s b}(z) \cdot \sin (\beta(z))+\sigma_{s b}(z) \cdot \cos (\beta(z))\right] d z}^{\text {shear-transfer due to smeared cracking }} \\
& \text { shear-transfer due to localized cracking } \\
& +\overbrace{2 \cdot \pi \cdot \int_{z_{t r}}^{d} \frac{r(z)}{\sin (\beta(z))} \cdot\left[\tau_{\text {agg }}(z) \cdot \sin (\beta(z))+\sigma_{\text {agg }}(z) \cdot \cos (\beta(z))\right] d z} \\
& \text { dowel-action } \\
& +\overbrace{V_{D A}}
\end{aligned}
$$

Each point of the failure criterion is numerically determined calculating the resistance associated with a given rotation $\psi$ by searching for the applied shear deformation $\delta_{s}$ that maximizes the shear strength of the CSC. Failure, defined as the intersection of the failure criterion and the load-rotation relationship, provides thus not only the punching strength $V_{R, \text { calc }}$ but also the associated deformation capacity characterized by the rotation $\psi_{R}$ and shear deformation at failure $\delta_{s, R}$.

\section{4 | COMPARISON AGAINST EXPERIMENTAL RESULTS}

The model presented in section 3 is compared with a database of experimental tests in this section. The database presented by Muttoni et $\mathrm{al}^{30}$ (including 121 experimental tests) is completed with tests from other authors (Elstner and Hognestad ${ }^{5}$; Kinnunen and Nylander ${ }^{15}$; Moe $^{7}$; Guandalini et al, ${ }^{49}$ and Inácio et al. $^{75}$ ), leading to a total of 133 specimens (where $B=1.27-6.00 \mathrm{~m}, d=0.096-0.456 \mathrm{~m}, r_{c}=0.042-0.451 \mathrm{~m}$, $c=0.130-0.520 \mathrm{~m}, f_{c}=12.8-130.1 \mathrm{MPa}, d_{g}=4-38.1 \mathrm{~mm}$, $\left.\rho=0.32-3.70 \%, f_{y}=321-720 \mathrm{MPa}\right)$.

The model shows an excellent agreement with the experimental results, leading to an average measured-tocalculated punching strength of 1.08 and a coefficient-ofvariation $(\mathrm{COV})$ of $7.9 \%$. The main results are plotted in Figure 18 as a function of the effective depth, flexural reinforcement ratio, concrete compressive strength, equivalent slab radius-to-effective depth ratio, column radius-toeffective depth ratio, and maximum aggregate size. Figure 18 shows that the model captures in a systematic manner the influence of the main geometrical and mechanical properties, without any noticeable trend.

The model is also compared with some selected series of experimental tests in Figure 19, showing that the 
(a)

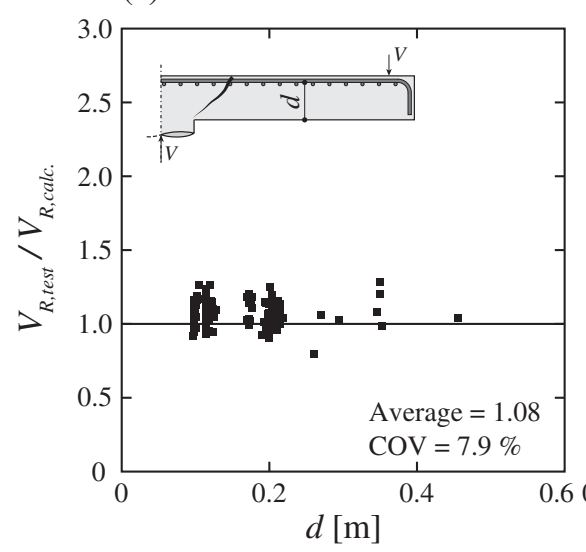

(d)

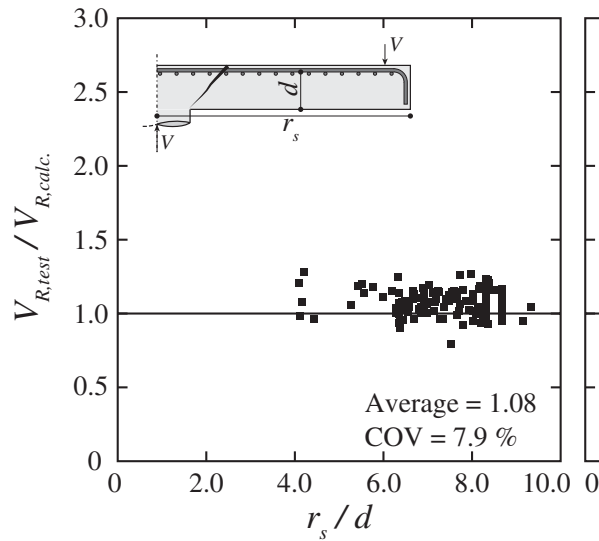

(b)

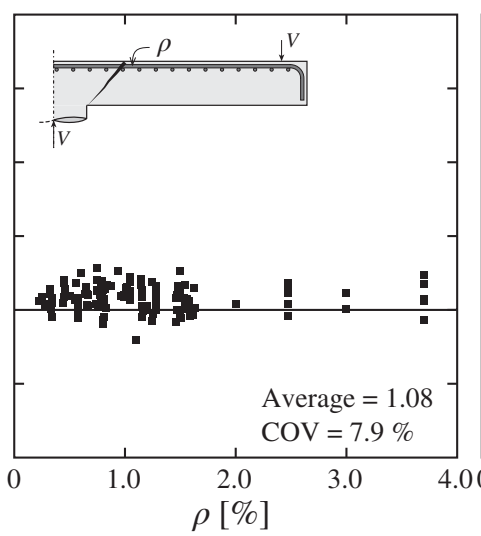

(e)

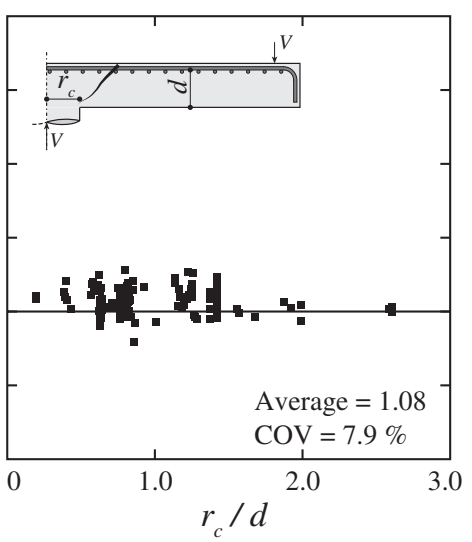

(c)

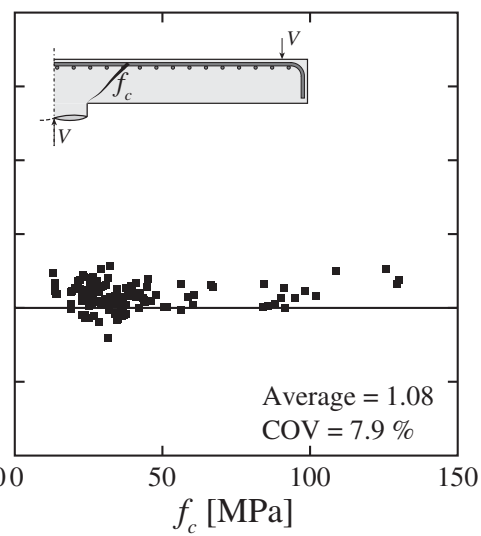

(d)

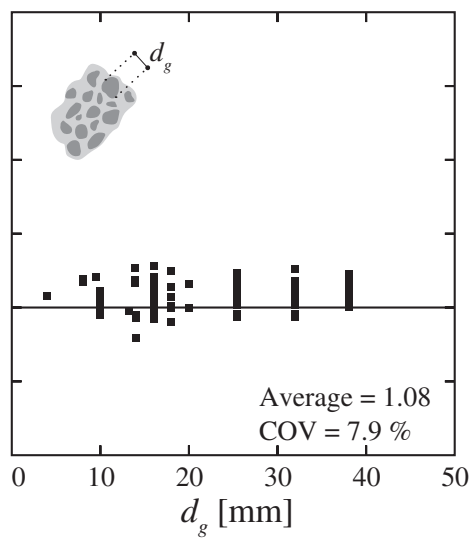

FIGURE 18 Ratio of experimental-to-calculated resistance as a function of (total of 133 specimens): (a) effective depth; (b) flexural reinforcement ratio; (c) concrete compressive strength; (d) equivalent radius of the slab-to-effective depth ratio (equivalent radius of an axisymmetric slab calculated ensuring equal flexural capacity); (e) column radius-to-effective depth ratio; (f) maximum aggregate size

influence of all investigated parameters is consistently addressed. In addition, the contributions of dowel action, localized and smeared cracking are also presented in Figure 19. It should be noted that the relative contributions of the smeared and localized cracking regions depend upon the definition of the transition between the two regimes. Other criteria for defining the transition will have little influence on the total strength but would influence the relative contributions of each region.

Figure 19b shows that the decrease of the normalized punching strength with the increase of concrete compressive strength is mainly related to the decrease of the shear-transfer contribution in the region with smeared cracking. This result is a consequence of the increased brittleness of the compressive behavior of high-strength concrete, which leads to an increased gradient of stresses along the CSC at failure.

Figure 19d,e shows a decrease of the normalized punching strength with increasing column size, resulting also mainly from the decrease of the contribution in the smeared cracking region. This is a consequence of the larger rotations at failure, which lead to larger crack openings and, consequently, to smaller extents of the region governed by smeared cracking.

Conversely, it can be noted that the contribution of the smeared cracking region to the strength increases at a higher rate than the contribution related to localized cracking with increasing flexural reinforcement ratio (Figure 19f). This can be justified by the decrease of the rotations at failure for increasing flexural reinforcement ratio, which leads to lower crack openings and, consequently, to larger extents of the region with smeared cracking behavior.

It should also be noted that the contribution of dowel action of flexural reinforcement bars is null or negligible in most of cases due to yielding of the flexural reinforcement at $r_{0}$. Thus, dowel action can only be activated in failures with small rotations, that is, members with reduced slenderness (Figure 19c) or members with large flexural reinforcement ratios (Figure 19f).

\section{I VALIDATION OF THE FAILURE CRITERION OF CSC THEORY}

As discussed by Muttoni et $\mathrm{al}^{30}$ the calculation of the punching strength by integration of stresses along the CSC is not suitable for design purposes. For that reason, assuming that the width of the CSC $(w)$ is proportional to the product of the slab rotation $(\psi)$ times the effective depth $(d)$ for the case of slender slabs $(w \propto \psi \cdot d)$, Muttoni ${ }^{22}$ 
(a)

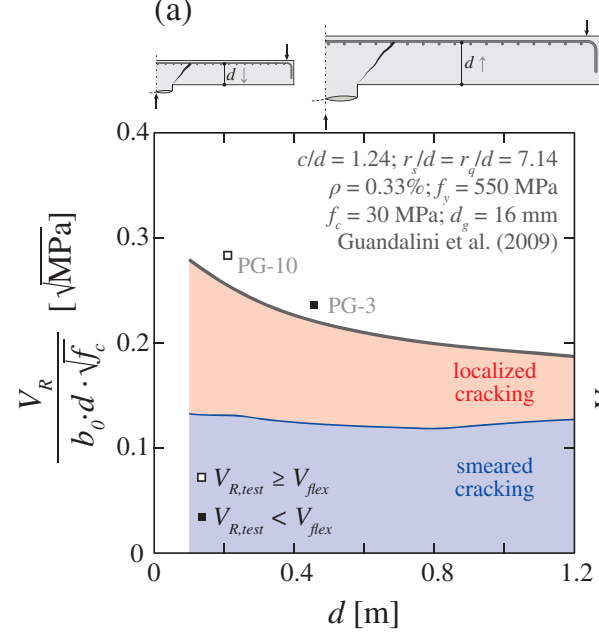

(d)

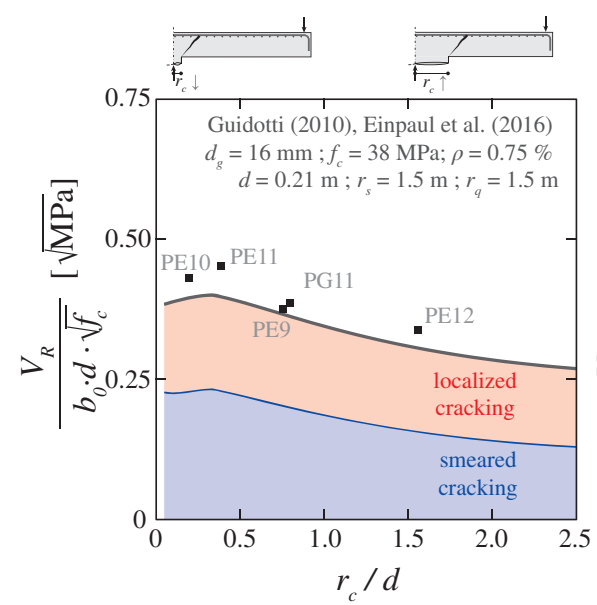

(b)

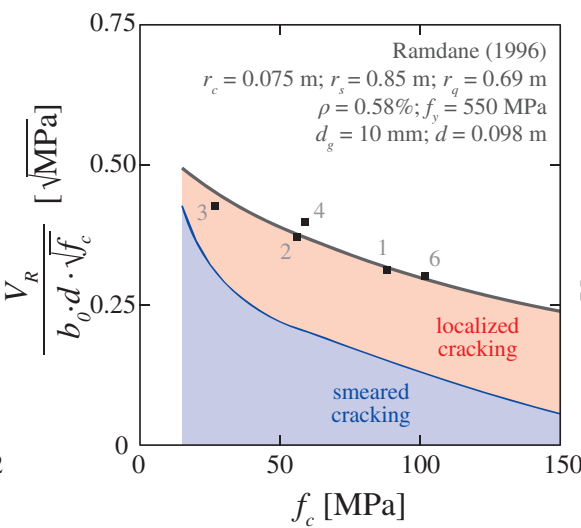

(e)

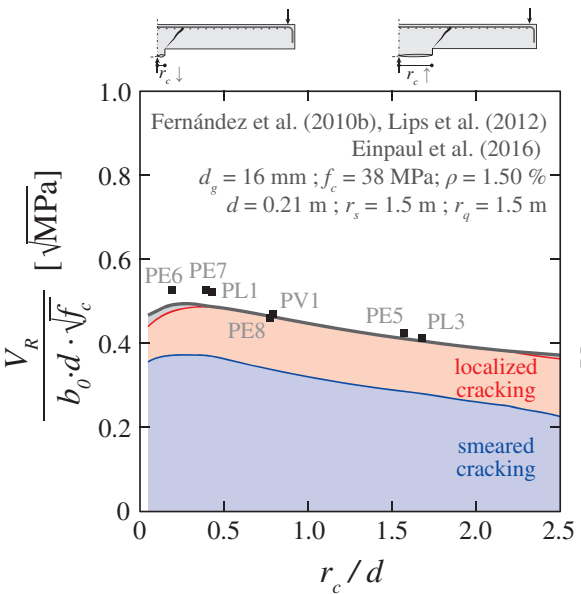

(c)

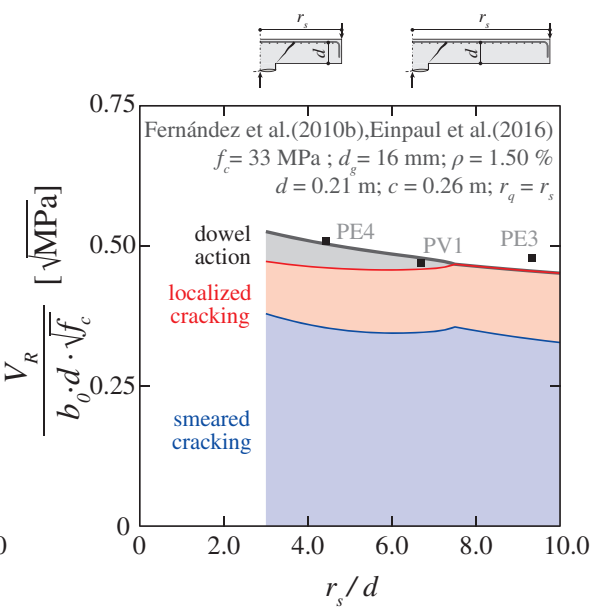

(f)

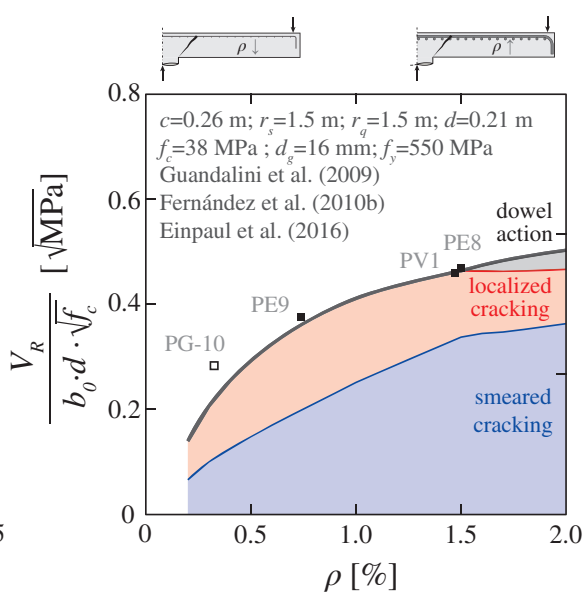

FIGURE 19 Comparison of the punching resistance calculated with the mechanical model against experimental test series where the following parameters were varied: (a) effective depth ${ }^{44}$; (b) concrete compressive strength $^{76}$; (c) slab radius-to-effective depth ratio ${ }^{46,77}$; (d) and (e) column radius-to-effective depth ratio ${ }^{31,46,77,78}$; (f) flexural reinforcement ratio ${ }^{46,49,77}$

proposed the following simplified failure criterion (see Figure $1 \mathrm{~b}$ for agreement with experimental results):

$$
\frac{V_{R}}{b_{0} \cdot d \cdot \sqrt{f_{c}}}=\frac{3 / 4}{1+15 \cdot \frac{\psi \cdot d}{d_{g 0}+d_{g}}},
$$

where units are in SI $(\mathrm{N}, \mathrm{mm}), V_{R}$ is the punching shear strength, $f_{c}$ the cylinders concrete compressive strength, $b_{0}$ the control perimeter located at $d / 2$ from the supported area, $d_{g}$ the aggregate size and $d_{g 0}$ the reference aggregate size $\left(d_{g 0}=16 \mathrm{~mm}\right.$ for normal weight concrete $\left.^{22}\right)$.

Some refinements based on theoretical considerations (transition from slender slabs to footings ${ }^{30}$ ) have recently been proposed leading to a power-law failure criterion (that can be used additionally to derive closed-form design expressions ${ }^{30}$ ):

$$
\frac{V_{R}}{b_{0} \cdot d \cdot \sqrt{f_{c}}}=0.55 \cdot\left(\frac{d_{d g}}{25 \cdot \psi \cdot d}\right)^{2 / 3} \leq 0.55
$$

where units are in SI $(\mathrm{N}, \mathrm{mm}), d_{d g}$ represents the reference value of roughness of the failure surface, whose value was defined in Equation (30). ${ }^{30}$
The hyperbolic (Equation (47)) and power-law (Equation (48)) failure criteria of CSCT are depicted in Figure 20a together with the numerical results of the model presented in section 3 corresponding to the experimental tests of the database. It is interesting to note that all points (every point representing the numerical results of an experimental test) concentrate in a narrow band with a clear trend of decreasing punching shear strength with increasing rotation. In the refined mechanical model, the decay of the contributions of the different shear-transfer actions with increasing rotation results mainly from the: (a) larger crack openings associated with flexural deformations which decrease the extent of the region with smeared cracking (thus decreasing its contribution); (b) strain softening in the shear band; (c) larger crack opening along the CSC which reduces its capacity to transfer stresses due to aggregate interlock (localized cracking); (d) increased stresses in the flexural reinforcement decreasing the capacity of transferring shear forces by dowel action. It can also be seen that both simplified 
(a)

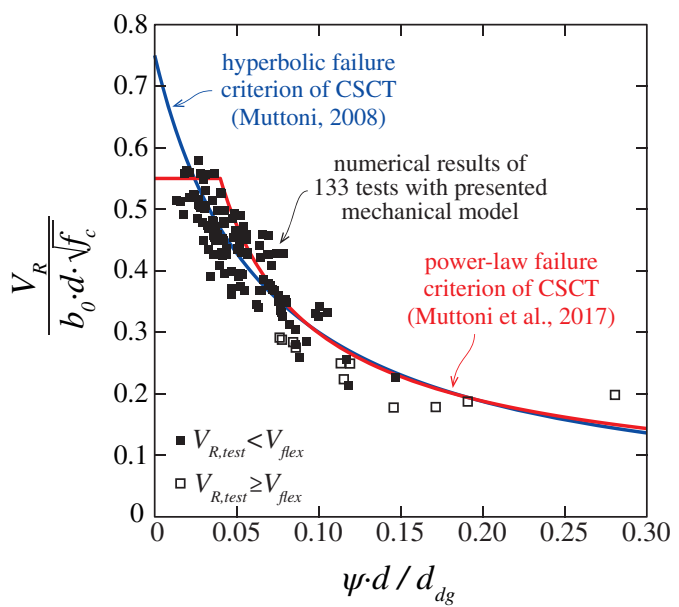

(b)

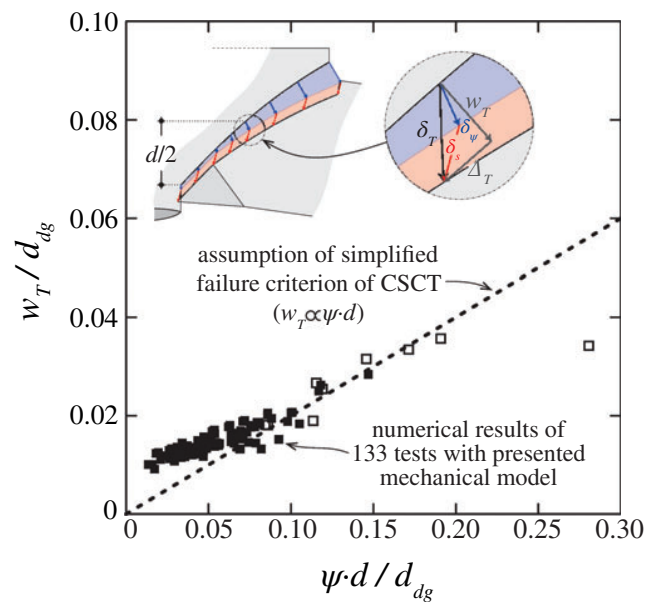

FIGURE 20 Results of the refined calculation of the failure criterion of critical shear crack theory (CSCT): (a) calculated punching shear strength as a function of the rotation and comparison with hyperbolic ${ }^{22}$ ) and power-law failure criteria ${ }^{30}$; (b) calculated crack opening at $d / 2$ from the soffit of the slab as a function of normalized rotation and comparison with assumption of simplified criteria of CSCT

failure criteria approximate fairly well the numerical results (a detailed comparison is presented in Table 1).

With respect to the original assumption of Muttoni ${ }^{22}$ that the crack opening is correlated to the product of the effective depth times the rotation of the slab $(w \propto \psi$. d), its validity can also be verified with the refined mechanical model. At failure, the opening of the CSC depends on the rotation of the slab $(\psi)$ and on its shear deformations $\left(\delta_{s}\right)$. As shown in Figure 20b, where the normalized crack opening at failure calculated at $d / 2$ from the soffit of the slab is plotted as a function of the normalized rotation, a clear correlation between both parameters appears. As suggested by Muttoni et al, ${ }^{30}$ this is justified by the fact that a larger initial crack opening (associated with larger rotations) also requires a larger crack sliding to activate the shear-transfer actions. It can be noted that for slabs whose failure load is governed by bending (empty squares in Figure 20b) this assumption seems to be conservative in cases where very large rotations are experienced.

The mechanical model can also be used to parametrically verify the simplified failure criteria (hyperbolic and power-law expressions), refer to Figure 21. The influence of the concrete compressive strength, column size, and slenderness is investigated separately in that figure, where the internal stresses developing along the CSC are also represented for small, moderate and large rotation conditions (smeared

TABLE 1 Summary of obtained experimental-to-calculated resistance $V_{R, \text { test }} / V_{R, \text { calc. }}$ of 133 specimens combining the load-rotation relationship according to Muttoni ${ }^{22}$ and the different failure criteria of critical shear crack theory (CSCT)

\begin{tabular}{|c|c|c|}
\hline Failure criterion & Average & $\operatorname{COV}(\%)$ \\
\hline Numerical integration of the refined model & 1.08 & 7.9 \\
\hline $\begin{array}{l}\text { Hyperbolic failure criterion (Equation (47)) })^{22} \\
\text { with } d_{d g} \text { of Equation }(30)^{30}\end{array}$ & 1.08 & 8.0 \\
\hline Power-law failure criterion (Equation (48)) ${ }^{30}$ & 1.03 & 8.4 \\
\hline
\end{tabular}

and localized cracking represented in dark and light blue, respectively). The parametric study shows overall consistent results with suitable predictions of the trends.

With respect to size effect, the results of the numerical integration of internal stresses are shown in Figure 22a, where three different cases (corresponding to different flexural reinforcement ratios) are represented and compared to the analytical failure criteria of the CSCT. The results show again fine agreement. In fact, a more detailed analysis shows that the size effect predicted by the numerically calculated failure criterion leads to a slope of approximately $-1 / 3$ in a double-log scale (Figure 22b). Thus, the size-effect law predicted by the refined mechanical model is milder when compared to the size-effect law resulting from the application of linear elastic fracture mechanics, which is of $-1 / 2$ in a double-log scale ${ }^{14}$. This result is consistent with the theoretical works of Fernández Ruiz and Muttoni ${ }^{25}$ and is justified by the fact that the slab behavior in terms of the load-deformation response is not linear (but highly non-linear).

\section{6 | CONCLUSIONS}

This paper validates the principles of the CSCT for punching shear failures of members without transverse reinforcement by means of a refined mechanical model. The refined mechanical model is supported on the analysis of recent experimental results available in the scientific literature, which show that:

1. The development of a CSC governs the punching strength of flat slabs as its opening disturbs the compression struts-carrying shear. Failure may occur by localization of the strains in this crack or by the opening of a new one (failure crack) due to the transverse tensile (splitting) stresses developed near the supported area. This is also consistent with the experimental 
(a)

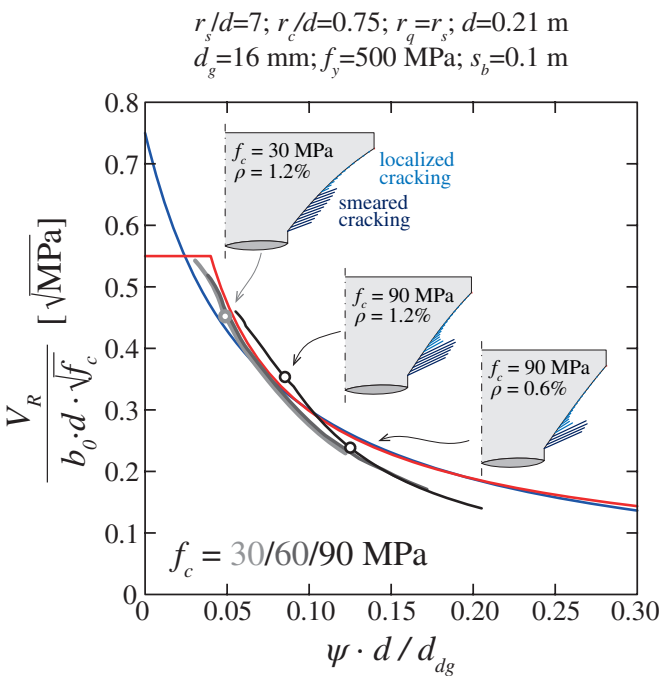

(b)

$r_{s} / d=7 ; r_{q}=r_{s} ; d=0.21 \mathrm{~m} ; f_{c}=30 \mathrm{MPa}$ $d_{g}=16 \mathrm{~mm} ; f_{y}=500 \mathrm{MPa} ; s_{b}=0.1 \mathrm{~m}$

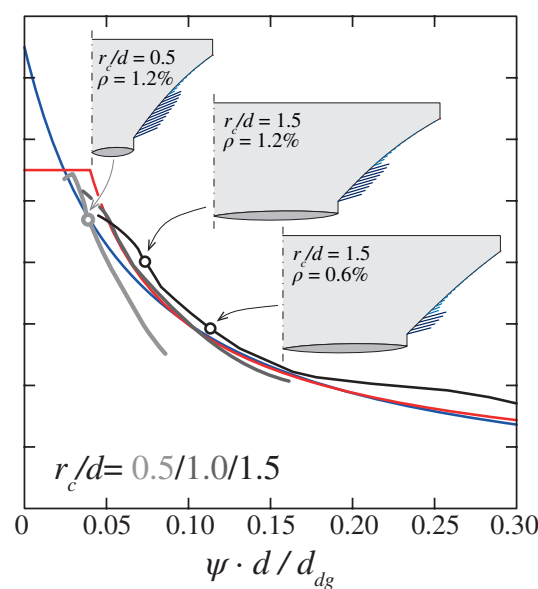

(c)

$$
\begin{aligned}
& r_{q}=r_{s} ; r_{c} / d=0.75 ; d=0.21 \mathrm{~m} ; f_{c}=30 \mathrm{MPa} \\
& d_{g}=16 \mathrm{~mm} ; f_{y}=500 \mathrm{MPa} ; s_{b}=0.1 \mathrm{~m}
\end{aligned}
$$

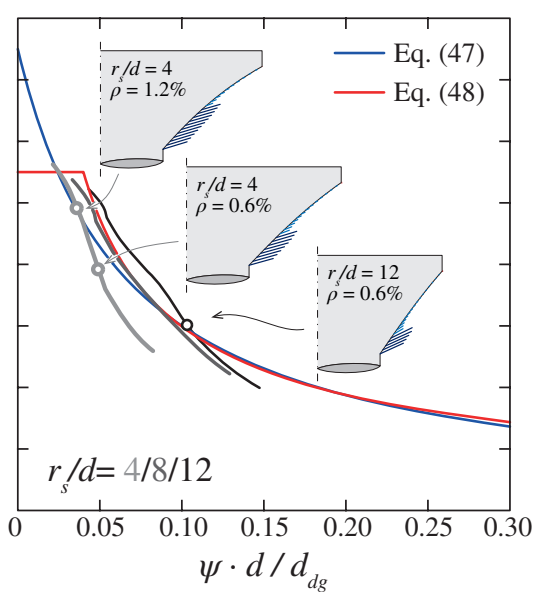

FIGURE 21 Comparison of the normalized punching strength calculated with the mechanical model against the hyperbolic ${ }^{22}$ and power-law (Muttoni et $\mathrm{a}^{30}$ ) failure criteria of CSCT for $\rho=0.3-3.0 \%$ with varying: (a) concrete compressive strength; (b) column radius-to-effective depth ratio; (c) slab radiusto-effective depth ratio

measurements of Einpaul et $\mathrm{al}^{38}$ based on measurements of internal cracking in punching tests.

2. The kinematics of a slab sector is governed at failure by the rotations of the slab as well as by the shear deformations developing in the CSC according to the experimental results of Clément. ${ }^{32}$

3. Two different regions can be distinguished in the CSC: a region where localized cracking occurs and a region where smeared cracking develops (in agreement with Muttoni et $\mathrm{al}^{30}$ ). This latter region is considered as a shear band, eventually failing by coalescence of cracks.

Based on the three previously described experimental evidences, a refined mechanical model is developed considering that the shear-transfer capacity of the region with localized cracking is mostly governed by aggregate interlock, while in the shear band, an inclined compression strut allows for the transfer of shear forces. In addition, it is considered that dowelling of the flexural reinforcement may develop. The main results of the refined mechanical model are listed below:

1. All the shear-transfer actions decay with increasing rotation as a consequence of larger crack openings. This is justified by the fact that larger crack openings reduce the aggregate interlock action, soften concrete in compression and limit the dowelling capacity of bars (by a reduction of the tensile strength of the concrete cover and due to yielding of the bars). (a)

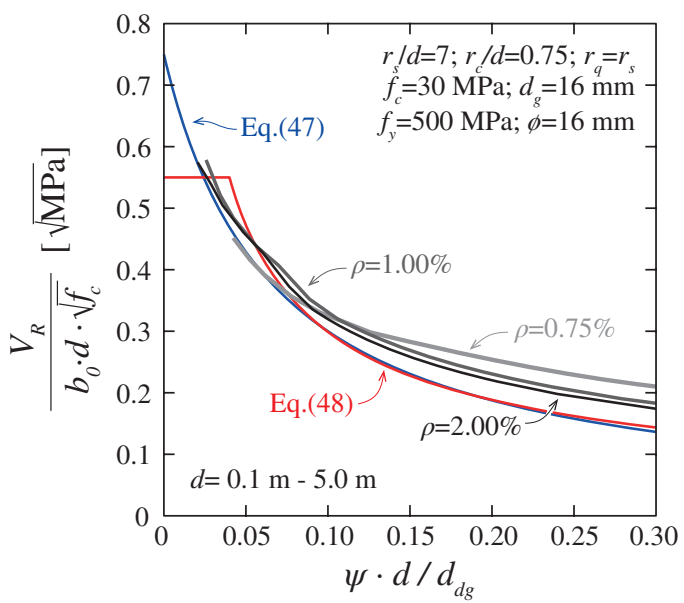

(b)

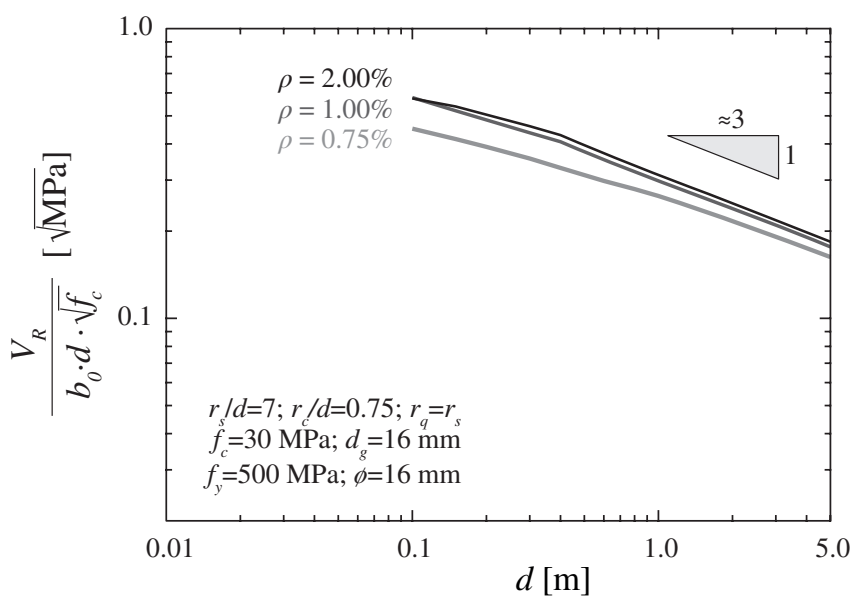

FIGURE 22 Investigation of size effect with the numerical integration of the failure criterion (calculated by varying only the effective depth $d$ ): (a) comparison with the analytical failure criteria of critical shear crack theory (CSCT); (b) calculated size-effect law represented in a double logarithmic scale 
2. A parametric study based on the refined mechanical model confirms the validity of the simplified failure criteria proposed by the CSCT.

3. The assumption of a crack opening correlated to the multiplication of the rotation by the effective depth ( $w$ $\propto \psi . d$ ) considered by Muttoni ${ }^{22}$ when proposing the simplified failure criterion of the CSCT can be justified on the basis of the proposed refined mechanical model, as there exists a correlation at failure between the rotations of the slab and the opening of the CSC.

4. The refined mechanical model predicts a size-effect law with a slope of approximately $-1 / 3$ in a doublelogarithmic scale. This result is in agreement with the theoretical works of Fernández Ruiz and Muttoni. ${ }^{25}$

5. The results of the model show a good agreement with experimental results when compared to a database of tested specimens as well as individual series of tests where only one parameter is varied.

\section{NOTATIONS}

$b_{0}$

$c$

$d$

$d_{g}$

$d_{d g}$

$f_{c}$

$f_{c, e f f}$

$n_{c r}$

$r_{C R}, z_{C R}$

$r_{c}$

$r_{O}$

$r_{\chi r}$

$s_{f}$

$u_{\psi}, v_{\psi}$

$w_{c}$

$w_{\psi}$,

$w_{S}, w_{T}$

$w_{C S C, z}$

$\bar{w}, \bar{\Delta}$ length of control perimeter

side length of a square column

effective depth of the slab

maximum aggregate size

reference value of the roughness of the CSC

concrete compressive strength measured in cylinders

peak stress of $\varepsilon_{3}-\sigma_{3 \text {,eff }}$ relationship accounting for imposed transverse tensile strain number of cracks

radial and vertical coordinates of the center of rotation

radius of a circular column

radial distance between the axis of the column and the CSC at the level of the flexural reinforcement $\left(r_{0, \text { test }}\right.$ for distance experimentally measured)

radii of region with non-negligible radial deformation

distance between primary flexural cracks

radial and vertical components (resp.) of vector of displacement due to rotation crack opening associated with a zero normal stress due to residual tensile strength crack opening (displacement normal to the CSC) due to rotation, shear deformation, and combined effect (vector sum), respectively

width of the CSC at the vertical coordinate $z$

normalized displacement normal and parallel (resp.) to the crack surface $x$

$z_{t r}$

$B$

$E_{c}, E_{s}$

$E_{c, e f f}$

$M_{d a}$

V

$V_{d a, b a r, \max }$

$V_{d a, b a r}$

$V_{\text {flex }}$

$V_{R}$

$\alpha_{\psi}, \alpha_{s}, \alpha_{T}$

$a_{1} a_{s} \alpha_{T}$ an

$\alpha_{c}$

$\bar{\alpha}$

$\beta$

$\gamma_{0}$

$\gamma_{\psi}, \gamma_{s}, \gamma_{T}$

$\delta_{\psi}, \delta_{s}, \delta_{T}$

$\varepsilon_{1, s b}, \varepsilon_{3, s b}$

$\varepsilon_{1, p}, \varepsilon_{3, p}$

$\varepsilon_{3, p, e f f}$

$\varepsilon_{c, r, t o p}$

$\varepsilon_{c, r, \text { soffit }}$

$\varepsilon_{s}$

$\kappa_{b}$

$\psi$

$\psi_{C S C}$

$\psi_{R}$

$\theta_{s b}$

$\lambda$

$\phi$

$\rho$ depth of neutral axis

vertical coordinate where transition from localized and smeared cracking occurs side length of a square slab

modulus of elasticity of concrete and reinforcement, respectively

effective modulus of elasticity of concrete acting moment in the bar due to dowel action

punching shear force

maximum shear force in the bar due to dowel action

acting shear force in the bar due to dowel action

flexural strength of an isolated specimen

punching shear strength $\left(V_{R, \text { test }}\right.$ for experimentally measured value)

angle between vertical axis and vector of displacement due to rotation, shear deformation, and combined effect (vector sum), respectively

factor accounting for brittleness of concrete on the $\varepsilon_{3}-\sigma_{3}$ relationship

factor accounting for brittleness of concrete 1.1 on the $\varepsilon_{3}-\sigma_{3, \text { eff }}$ relationship for $\kappa_{b}$

secant angle of the CSC

angle between CSC and vector of displace- 0

ments due to shear deformation at $z$

angle between CSC and vector of displace-

ment due to rotation, shear deformation,

and combined effect (vector sum),

respectively

sliding due to rotation, shear deformation, and combined effect (resp.)

principal tensile and compressive radial strains in the shear band

strains at the peak of the $\varepsilon_{1}-\sigma_{3}$ and $\varepsilon_{3}-\sigma_{3}$ relationships (resp.)

peak strain of $\varepsilon_{3}-\sigma_{3, \text { eff }}$ relationship accounting for imposed transverse tensile strains

radial strain at the concrete top and bottom

(soffit) surface of the slab

strain in the flexural reinforcement bars at $r_{0}$

factor accounting for the increase of the peak stress and strain in the $\varepsilon_{3}-\sigma_{3}$ due to biaxial compression

rotation of the slab

rotation of the slab at the CSC

rotation of the slab at failure

direction of principal compressive strain

thickness of the shear band

diameter of the bar

flexural reinforcement ratio 


\begin{tabular}{|c|c|}
\hline $1, s b, \sigma_{3, s b}$ & $\begin{array}{l}\text { principal tensile and compres } \\
\text { the shear band (resp.) }\end{array}$ \\
\hline$\sigma_{s}$ & $\begin{array}{l}\text { stress in the flexural reinforcement bars } \\
\text { at } r_{0}\end{array}$ \\
\hline$\sigma_{\text {agg }}, \tau_{\text {agg }}$ & $\begin{array}{l}\text { normal and shear stresses associated with } \\
\text { aggregate interlock, respectively }\end{array}$ \\
\hline$\sigma_{f c t}$ & $\begin{array}{l}\text { normal stress due to residual tensile } \\
\text { strength }\end{array}$ \\
\hline$\sigma_{t}$ & $\begin{array}{l}\text { reduced tensile resistance of spalled } \\
\text { concrete }\end{array}$ \\
\hline$\tau_{l}$ & $\begin{array}{l}\text { shear stresses causing flexural crack to } \\
\text { become inclined flexural cracks governing } \\
\text { the shape of the CSC }\end{array}$ \\
\hline$\rfloor_{\psi}, \Delta_{s}, \Delta_{T}$ & $\begin{array}{l}\text { displacement parallel to the CSC due } \\
\text { rotation shear deformation and combin }\end{array}$ \\
\hline
\end{tabular}

\section{ORCID}

João T. Simões (D) http://orcid.org/0000-0002-7773-9554

Miguel Fernández Ruiz (D) http://orcid.org/0000-0001-6720-8162

\section{REFERENCES}

1. fib. Punching of structural concrete slabs, fib Bulletin; 2001, 12, 314.

2. fib. Punching shear of structural concrete slabs. fib-ACI Bulletin; 2017,81 .

3. Polak MA. Punching Shear in Reinforced Concrete Slabs. Vol 232. ACI Special Publication: Farmington Hills, MI; 2005:302.

4. Regan PE, Braestrup MW. Punching Shear in Reinforced Concrete. Comité Euro-International du Béton, Bulletin No. 168; 1985:232.

5. Elstner RC, Hognestad E. Shearing strength of reinforced concrete slabs. ACI Maters J. 1956;53(2):29-58.

6. Hognestad E. Shearing strength of reinforced concrete column footings. ACI J. 1953;25(3):189-208.

7. Moe J. Shearing Strength of Reinforced Concrete Slabs and Footings under Concentrated Loads. PCA: Skokie, Illinois; 1961:D47.

8. Richart FE. Reinforced concrete walls and column footings, part 1 and 2 . ACI J. 1948;45: pp. 97-127, pp. 237-260.

9. Whitney CS. Ultimate shear strength of reinforced concrete flat slabs, footings, beams, and frame members without shear reinforcement. ACI J Proc. 1957;54(10):265-298.

10. American Concrete Institute Committee 318. Building Code Requirements for Reinforced Concrete (ACI 318-14). Farmington Hills, MI: American Concrete Institute; 2014.

11. CEN. Eurocode 2: Design of Concrete Structures-Part 1-1: General Rules and Rules for Buildings. Brussels, Belgium: European Committee for Standardization (CEN); April 2004:225.

12. Braestrup MW, Nielsen MP, Jensen BC, Bach F. Axisymmetric punching of plain and reinforced concrete, Report No.75. DTU: Denmark; 1976, 33.

13. Hoang LC. Punching shear analysis according to the crack sliding model slabs without shear reinforcement. Proc Danish Soc Struct Sci Eng. 2006; 77(3):69-133.

14. Bazant ZP, Cao Z. Size effect in punching failure of slabs. ACI Struct J. 1987;84(1):44-53.

15. Kinnunen S, Nylander H. Punching of concrete slabs without shear reinforcement. Trans Roy Inst Technol. 1960;158:112.

16. Shehata IAEM, Regan PE. Punching in R.C. slabs. ASCE J Struct Eng 1989;115(7):1726-1740.

17. Broms CE. Punching of flat plates - a question of concrete properties in biaxial compression and size effect. ACI Struct J. 1990;87(3):292-304.

18. Broms CE. Concrete Flat Slabs and Footings - Design Method for Punching and Detailing for Ductility [doctoral thesis]. Stockholm, Sweden: KTH; $2005,114$.
19. Broms CE. Tangential strain theory for punching failure of flat slabs. $A C I$ Struct J. 2016;113(1):95-104

20. Hallgren M. Punching Shear Capacity of Reinforced High Strength Concrete Slabs [doctoral thesis]. Stockholm, Sweden; KTH; 1996, 206.

21. Muttoni A, Schwartz J. Behaviour of beams and punching in slabs without shear reinforcement. Presented at: IABSE Colloquium. 1991, 62; IABSE: Stuttgart, Germany, 703-708.

22. Muttoni A. Punching shear strength of reinforced concrete slabs without transverse reinforcement. ACI Struct J. 2008;105(4):440-450.

23. Park H-G, Choi K-K, Chung L. Strain-based strength model for direct punching shear of interior slab-column connections. Eng Struct. 2011;33: 1062-1073.

24. Yankelevsky DZ, Leibowitz O. Punching shear in concrete slabs. Int $J$ Mech Sci. 1999;41:1-15.

25. Fernández Ruiz M, Muttoni A. Size effect in shear and punching shear failures: differences between statically determinate members and redundant structures. Struct Concr. 2017;1-11. https://doi.org/10.1002/suco.201700059

26. Cavagnis F, Fernández Ruiz M, Muttoni A. Shear failures in reinforced concrete members without transverse reinforcement - an analysis of the critical shear crack development on the basis of test results. Eng Struct. 2015; 103:157-173.

27. Cavagnis F, Fernández Ruiz M, Muttoni A. A mechanical model for failures in shear of members without transverse reinforcement based on development of a critical shear crack. Eng Struct. 2018;157:300-315.

28. Fernández Ruiz M, Muttoni A, Sagaseta J. Shear strength of concrete members without transverse reinforcement: a mechanical approach to consistently account for size and strain effects. Eng Struct. 2015;99:360-372.

29. Muttoni A, Fernández RM. Shear strength of members without transverse reinforcement as function of critical shear crack width. ACI Struct J. 2008; 105(2):163-172.

30. Muttoni A, Fernández RM, Simões JT. The theoretical principles of the critical shear crack theory for punching shear failures and derivation of consistent closed-form design expression. Struct Concr. 2017;1-17. https://doi. org/10.1002/suco.201700088

31. Guidotti R. Poinçonnement des planchers-dalles avec colonnes superposées fortement sollicitées [doctoral thesis]. Lausanne, Switzerland: EPFL; 2010, $4812,189$.

32. Clément $T$. Influence de la précontrainte sur la résistance au poinçonnement des dalles en béton armé [doctoral thesis]. Lausanne, Switzerland: EPFL; 2012, 5516, 222.

33. Simões JT, Bujnak J, Fernández RM, Muttoni A. Punching shear on compact footings with uniform soil pressure. Struct Concr. 2016a;17(4): 603-617.

34. Simões JT, Faria DMV, Fernández Ruiz M, Muttoni A. Strength of reinforced concrete footings without transverse reinforcement according to limit analysis. Eng Struct. 2016b;112:146-161.

35. Simões JT. The mechanics of punching in reinforced concrete slabs and footings without transverse reinforcement [doctoral thesis]. Lausanne, Switzerland: EPFL; 2018.

36. Campana S, Fernández Ruiz M, Anastasi A, Muttoni A. Analysis of shear-transfer actions on one-way RC members based on measured cracking pattern and failure kinematics. Mag Concr Res. 2013;56(6):386-404.

37. Huber P, Huber T, Kollegger J. Investigation of the shear behavior of RC beams on the basis of measured crack kinematics. Eng Struct. 2016;113:41-58.

38. Einpaul J, Fernández Ruiz M, Muttoni A. Measurements of internal cracking in punching tests slabs without shear reinforcement. Mag Concr Res. 2017;1-27. https://doi.org/10.1680/jmacr.16.00099

39. Einpaul J. Punching Strength of Continuous Flat Slabs [doctoral thesis] Lausanne, Switzerland: EPFL; 2016, 6928, 209.

40. Krefeld WJ, Thurston CW. Contribution of longitudinal steel to shear resistance of reinforced concrete beams. ACI J Proc. 1966;63(3):325-344.

41. Fernández Ruiz M, Plumey S, Muttoni A. Interaction between bond and deviation forces in spalling failures of arch-shaped members without transverse reinforcement. ACI Struct J. 2010a;107:346-354.

42. Fernández Ruiz M, Mirzaei Y, Muttoni A. Post-punching behavior of flat slabs. ACI Struct J. 2013;110:801-812.

43. Jacobsen JS, Olesen JF, Poulsen PN. Constitutive Mixed Mode Behavior of Cracks in Concrete: Experimental Investigations of Material Modeling. Kgs. Lyngby: Technical University of Denmark. (BYGDTU Report); 2012, 169 p.

44. Guandalini S. Symmetric Punching Shear of Reinforced Concrete Slabs (in French) [doctoral thesis]. Lausanne, Switzerland: EPFL; 2005, 3380, 289. 
45. Tassinari L. Poinçonnement symétrique des dalles en béton armé avec armature de poinçonnement [doctoral thesis]. Lausanne, Switzerland: EPFL; 2011, 5030, 197.

46. Fernández Ruiz M, Muttoni A, Kunz J. Strengthening of flat slabs against punching shear using post-installed shear reinforcement. ACI Struct J. 2010b;107(4):434-442.

47. Lips S. Punching of Flat Slabs with Large Amounts of Shear Reinforcement [doctoral thesis]. Lausanne, Switzerland: EPFL; 2012, 5409, 217.

48. Drakatos IS. Seismic Behaviour of Slab-Column Connections Without Transverse Reinforcement [doctoral thesis]. Switzerland: EPFL, Lausanne; 2016, 7232, 196.

49. Guandalini S, Burdet O, Muttoni A. Punching tests of slabs with low reinforcement ratios. ACI Struct J. 2009;106(1):87-95.

50. Kanellopoulos A. Zum unelastischen Verhalten und Bruch von Stahlbeton [doctoral thesis]. Zürich, Switzerland: ETHZ; 1986, 153, 86.

51. Vecchio FJ, Collins MP. The modified compression-field theory for reinforced concrete elements subjected to shear. ACI J. 1986;83(2):219-231.

52. Nielsen MP, Hoang LC. Limit Analysis and Concrete Plasticity. 3rd ed. Boca Raton, FL: CRC Press; 2011.

53. Khaja MN, Sherwood EG. Does the shear strength of reinforced concrete beams and slabs depend upon the flexural reinforcement ratio or the reinforcement strain? Can J Civil Eng. 2013;40:1068-1081.

54. Muttoni, A. The Applicability of the Theory of Plasticity in the design of reinforced concrete (in German) [doctoral thesis]. Zürich, Switzerland: ETHZ; 1989, 176, 159.

55. Walraven JC. Aggregate Interlock: A Theoretical and Experimental Analysis [doctoral thesis]. Delft, Netherlands: Delft University of Technology; 1980, 197.

56. Mansur MA, Vinayagam $T$, Tan KH. Shear transfer across a crack in reinforced high-strength concrete. J Mater Civil Eng. 2008;20(4):294-302.

57. Mattock AH. Effect of Aggregate Type on Single Direction Shear Transfer in Monolithic Concrete. Report SM74-2, Department of Civil Engineering, University of Washington, Seattle, Washington; 1974.

58. Walraven JC. Fundamental analysis of aggregate interlock. ASCE J Struct Eng. 1981;107(11):2245-2270.

59. Hordijk DA. Tensile and tensile fatigue behaviour of concrete, experiments, modelling and analyses. Heron. 1992;37(1):79 p.

60. fib (Fédération internationale du béton). fib Model Code for Concrete Structures 2010. Germany: Ernst \& Sohn; 2013:434.

61. Collins MP, Kuchma D. How safe are our large, lightly reinforced concrete beams, slabs, and footings? ACI Struct J. 1999;96(4):482-490.

62. Sherwood EG, Bentz EC, Collins MP. Effect of aggregate size on beam-shear strength of thick slabs. ACI Struct J. 2007;104(2):180-190.

63. Jensen BC. Lines of discontinuity for displacements in the theory of plasticity of plain and reinforced concrete. Mag Concr Res. 1975;2(2:143-150.

64. Bazant ZP, Xiang Y. Size effect in compression fracture: splitting crack band propagation. ASCE J Eng Mech. 1997;123(2):162-172.

65. Angelakos D, Bentz EC, Collins MP. Effect of concrete strength and minimum stirrups on shear strength of large members. ACI Struct J. 2001;98(3):290-300.

66. Bentz EC, Vecchio FJ, Collins MP. Simplified modified compression field theory for calculating shear strength of reinforced concrete elements. ACI Struct J. 2006;103(4):614-624.

67. Guidotti R, Fernández Ruiz M, Muttoni A. Crushing and Flexural Strength of Slab-Column Joints. Eng Struct. 2011;33(3):855-867.

68. Kupfer H, Hubert $\mathrm{KH}$, Rusch $\mathrm{H}$. Behavior of concrete under biaxial stresses. ACI J Proc. 1969;66(52):656-666.

69. Kupfer H, Gerstle H. Behavior of concrete under biaxial stresses. ASCE J Eng Mech. 1973;99(4):853-866.

70. Fernández Ruiz M, Muttoni A. On development of suitable stress fields for structural concrete. ACI Struct J. 2007;104(4):495-502.

71. Rasmussen BH. Betonindstøbte, tværbelastede boltes og dornes bæreevne (in Danish), Bygningsstatiske Meddelelser; 1963, 34(2):39-55.

72. Millard SG, Johnson RP. Shear transfer across cracks in reinforced concrete due to aggregate interlock and to dowel action. Mag Concr Res. 1984; 36(126):9-21.

73. Randl N. Design recommendations for interface shear transfer in fib Model Code 2010. Struct Concr. 2013;14:230-241.

74. Sorensen JH, Hoang LH, Olesen JF, Fischer G. Catenary action in rebars crossing a casting joint loaded in shear. 11th fib International PhD Symposium in Civil Engineering. 2016:735-742.

75. Inácio M, Ramos AP, Lúcio V, Faria DV. Punching of high strength concrete flat slabs-experimental investigation. Eng Struct. 2015;103:275-284.
76. Ramdane K-E. Punching shear of high performance concrete slabs. Proceedings of the Fourth International Symposium on Utilization of High-Strength/High Performance Concrete. Vol 3. 1996:1015-1026.

77. Einpaul J, Bujnak J, Fernández Ruiz M, Muttoni A. Study on influence of column size and slab slenderness on punching strength. ACI Struct J. 2016; 113(1):135-145.

78. Lips S, Fernández Ruiz M, Muttoni A. Experimental investigation on punching strength and deformation capacity of shear-reinforced slabs. $A C I$ Struct J. 2012;109:889-900.

\section{AUTHOR'S BIOGRAPHIES}

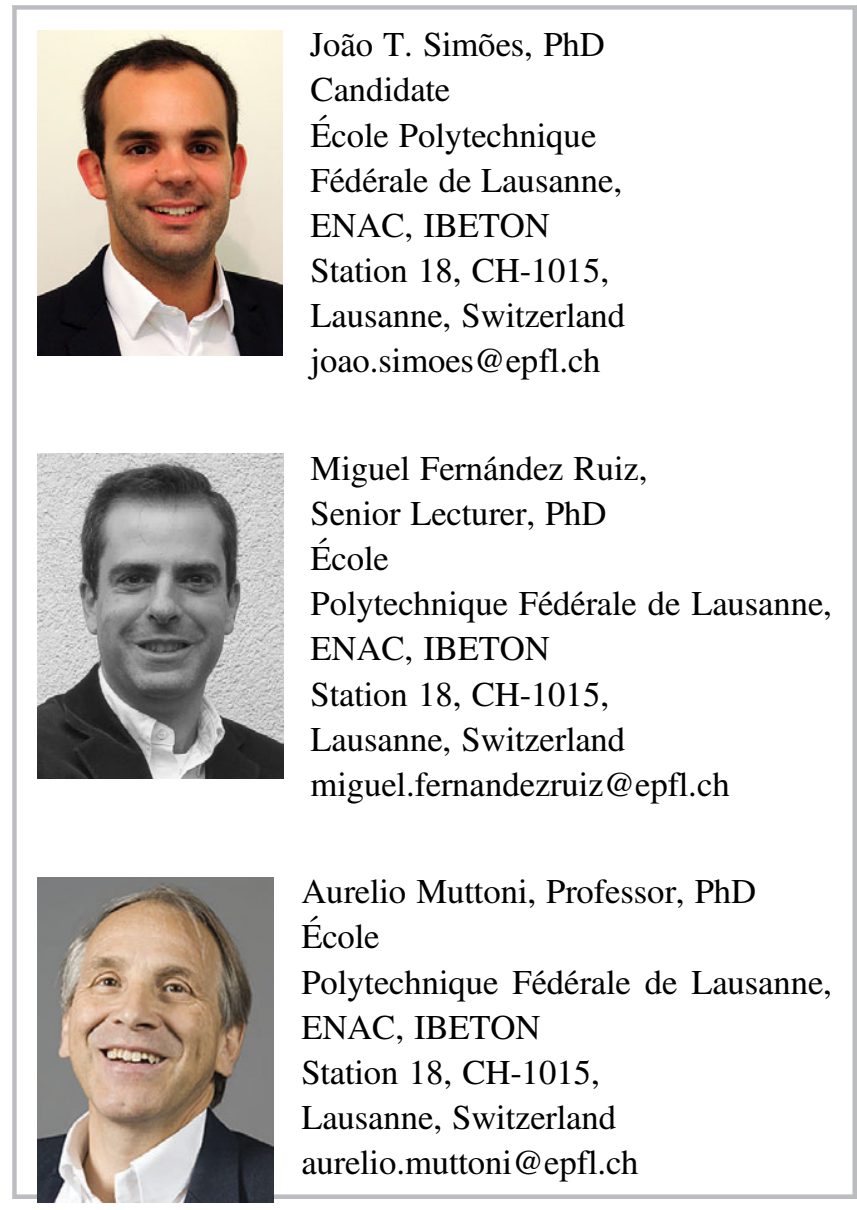

How to cite this article: Simões JT, Fernández Ruiz M, Muttoni A. Validation of the Critical Shear Crack Theory for punching of slabs without transverse reinforcement by means of a refined mechanical model. Structural Concrete. 2018;19:191-216. https://doi.org/10.1002/suco.201700280

\section{A. APPENDIX-CONSTITUTIVE RELATIONSHIPS ADOPTED FOR CONCRETE.}

\author{
A. 1 Triaxial behavior of concrete according to Guidotti \\ et $\mathbf{a l}^{67}$
}

This appendix describes the calculation of the longitudinal stress $\left(\sigma_{3}\right)$ and transverse strain $\left(\varepsilon_{1}\right)$ associated with a 
longitudinal strain $\left(\varepsilon_{3}\right)$ and confining pressure. For that purpose, the strain-stress relationship presented and experimentally validated by Guidotti et $\mathrm{al}^{67}$ is used in this work. The formulae of the mentioned relationship are briefly described in the following (please refer to Reference 67 for further details).

According to the relationship proposed by Guidotti et al, ${ }^{67}$ the compressive stress $\sigma_{3}$ is calculated as a function of the compressive strain $\varepsilon_{3}$ as follows:

$$
\sigma_{3}=\left(\alpha_{c c}-1\right) \frac{\varepsilon_{3} \cdot E_{c c}}{\alpha_{c c}-1+\left(\frac{\varepsilon_{3}}{\varepsilon_{3, p}}\right)^{\alpha_{c c}}},
$$

where $E_{c c}$ refers to the modulus of elasticity of confined concrete and $\varepsilon_{3, p}$ is the strain corresponding to the peak of the stress-strain relationship, whose values can be respectively computed as

$$
E_{c c}=\frac{E_{c}}{1-2 \cdot \nu_{c} \cdot \frac{\sigma_{l a t}}{f_{c}}}, \quad \varepsilon_{3, p}=-\frac{\alpha_{c c}}{\left(\alpha_{c c}-1\right)} \cdot \frac{f_{c c}}{E_{c c}},
$$

where

$$
\begin{gathered}
\alpha_{c c}=\frac{\alpha_{c}+40 \cdot \frac{\sigma_{\text {lat }}}{f_{c}}}{\zeta+\alpha_{c} \cdot(1-\zeta)+40 \cdot \frac{\sigma_{\text {lat }}}{f_{c}}} \text { with } \zeta=\frac{f_{c c}}{f_{c}} \cdot \frac{E_{c}}{E_{c c}} \text { and } \\
\alpha_{c}=1.5+\frac{f_{c}}{75}+\frac{f_{c}^{2}}{4500}\left(f_{c} \text { in MPa }\right)
\end{gathered}
$$

with the $\sigma_{\text {lat }}$ representing a lateral pressure, $\nu_{\mathrm{c}}$ representing the Poisson's coefficient and $f_{c c}$ referring to the concrete compressive strength under confined conditions, which can be calculated based on a Mohr-Coulomb yield criterion as $f_{c c}=f_{c}+k \cdot \sigma_{\text {lat }}$ with $k=(1+\sin (\varphi)) /(1-\sin (\varphi)) \approx 4$ for a concrete friction angle of $\varphi=37^{\circ} .{ }^{52}$ Guidotti et al ${ }^{67}$ also proposed formulae to calculate the transverse strain $\left(\varepsilon_{1}\right)$ associated with a given longitudinal strain $\left(\varepsilon_{3}\right)$.

\section{A.2 Strain-stress relationship adopted for the concrete in the smeared cracking region}

The strain-stress relationship proposed by Guidotti et $\mathrm{al}^{67}$ is adopted in this work in order to calculate the stress $\sigma_{3}$ in the smeared cracking region. As shown by Kupfer et al, ${ }^{68}$ the peak stress and the deformation capacity of concrete increase in the case of biaxial compression. As discussed in section 3.5.3, the region with smeared cracking is subjected to tangential compression due to both flexural and shear deformations. For this reason, the stress-strain relationship adopted for this region has to account for an increased peak stress and associated deformation. In this work, it is considered that the stress-strain relationship of the region with smeared cracking corresponds to the one of a cylinder with a lateral confining pressure leading to a peak stress of $\kappa_{b} \cdot f_{c}$ with $\kappa_{b}=1.1$ (see section 3.5 .3 for discussion on the value). With this respect, the formulae of Guidotti et al ${ }^{67}$ are simplified in order to: (a) to include a single parameter $\left(\kappa_{b}\right)$ increasing the peak strength and deformation capacity of the $\varepsilon_{3}-\sigma_{3}$ relationship; and (b) to have a $\varepsilon_{1}-\varepsilon_{3}$ relationship given by a single function. Therefore, the $\varepsilon_{3}-\sigma_{3}$ relationship adopted in this work consists on the one of Guidotti et al ${ }^{67}$ (Equation (A1)) as follows:

$$
\sigma_{3}=(\bar{\alpha}-1) \cdot \frac{\varepsilon_{3} \cdot E_{c}}{\bar{\alpha}-1+\left(\frac{\varepsilon_{3}}{\bar{\varepsilon}_{3, p}}\right) \bar{\alpha}},
$$

where $\bar{\varepsilon}_{3, p}$ is the modified peak strain and $\bar{\alpha}$ is the modified brittleness factor of the strain-stress relationship. The modified peak strain can be obtained based on Equation (A2) considering $f_{c c}=\kappa_{b} \cdot f_{c}, E_{c c} \approx E_{c}$ (low confinement pressures) and $\alpha_{c c}=\bar{\alpha}$ as:

$$
\bar{\varepsilon}_{3, p}=-\kappa_{b} \cdot \frac{\bar{\alpha}}{(\bar{\alpha}-1)} \cdot \frac{f_{c}}{E_{c}} .
$$

The value of the modified brittleness factor $\bar{\alpha}$ can be approximated from Equation (A3) for a constant value of the ratio $f_{c c} / f_{c}=\kappa_{b}$ only as a function of the value of $\alpha_{c}$. In this case, for $\kappa_{b}=1.1$, the value of $\bar{\alpha}$ can be reasonably estimated as:

$$
\bar{\alpha}=\frac{1+\alpha_{c}}{2-0.05 \cdot \alpha_{c}}
$$

with $\alpha_{c}$ calculated according to Equation (A3).

With respect to the $\varepsilon_{1}-\varepsilon_{3}$ relationship, a satisfactory agreement can be found with the parabola proposed by Guidotti et $\mathrm{al}^{67}$ in the range of strains of interest (descending branch of $\varepsilon_{1}-\sigma_{3}$ relationship) by considering the following third-degree parabola:

$$
\varepsilon_{1}=0.5 \cdot \frac{\varepsilon_{3}{ }^{3}}{\varepsilon_{0} \cdot \bar{\varepsilon}_{3, p}},
$$

where $\varepsilon_{0}$ refers to a reference strain taken equal to 0.0045 (fitting parameter to approximate the numerical results of Guidotti et al ${ }^{67}$ for the case of $f_{c c} / f_{c}=\kappa_{b}=1.1$ ).

\section{A.3 Calculation of $\varepsilon_{3, s b}-\sigma_{3, s b}$ relationship accounting for imposed transverse strains}

In the case where the imposed transverse tensile strain in the shear band $\varepsilon_{1, s b}$ does not exceed the transverse strain corresponding to the peak of the $\varepsilon_{1}-\sigma_{3}$ relationship $\left(\bar{\varepsilon}_{1, p}\right.$, back calculated with Equation (A7) and $\varepsilon_{3}=\bar{\varepsilon}_{3, p}$ ), it is assumed that any effect of strain softening occurs. In this case, the $\varepsilon_{3, s b}-\sigma_{3, s b}$ relationship is assumed to be equal to the $\varepsilon_{3}-\sigma_{3}$ relationship.

On the other hand, if the imposed transverse tensile strain in the shear band $\varepsilon_{1, s b}$ exceeds the transverse strain expected at the peak of the $\varepsilon_{1}-\sigma_{3}$ relationship $\left(\bar{\varepsilon}_{1, p}\right)$, the peak stress $\kappa_{b} \cdot f_{c}$ is replaced by an effective concrete compressive strength $f_{c, \text { eff. }}$. The value of $f_{c \text {, eff }}$ corresponds to the value of stress $\sigma_{3}$ obtained by introducing the value of the imposed strain $\varepsilon_{1, s b}$ in the strain-stress $\varepsilon_{1}-\sigma_{3}$ relationship. 
On that basis, the $\varepsilon_{3, s b}-\sigma_{3, s b}$ relationship can be mathematically computed in a general manner as follows:

$$
\sigma_{3, s b}=(\bar{\alpha}-1) \frac{\varepsilon_{3, s b} \cdot E_{c, e f f}}{\bar{\alpha}-1+\left(\frac{\varepsilon_{3, s b}}{\varepsilon_{3, p, e f f}}\right)^{\bar{\alpha}}},
$$

where the effective peak strain $\varepsilon_{3, p, e f f}$ and the effective modulus of elasticity of the concrete $E_{c, \text { eff }}$ are calculated as a function of the value of the imposed transverse tensile strain $\left(\varepsilon_{1, s b}\right)$. The effective peak strain is calculated with Equation (A7) by knowing that the point $\left(\varepsilon_{1}, \varepsilon_{3}\right)=\left(\varepsilon_{1, s b}, \varepsilon_{3, p, e f f}\right)$ :

$$
\varepsilon_{3, p, e f f}=\left\{\begin{array}{ll}
\bar{\varepsilon}_{3, p} & \text { if } \varepsilon_{1, s b} \leq \bar{\varepsilon}_{1, p} \\
\sqrt[3]{2 \cdot \varepsilon_{0} \cdot \bar{\varepsilon}_{3, p} \cdot \varepsilon_{1, s b}} & \text { if } \varepsilon_{1, s b}>\bar{\varepsilon}_{1, p}
\end{array} .\right.
$$

The effective modulus of elasticity of the concrete is calculated with Equation (A8) knowing that the curve passes through the point with coordinates at the peak $\left(\varepsilon_{3, p}\right.$,

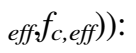

$$
E_{c, e f f}=\left\{\begin{array}{cc}
E_{c} & \text { if } \varepsilon_{1, s b} \leq \bar{\varepsilon}_{1, p} \\
\frac{\bar{\alpha}}{\bar{\alpha}-1} \cdot \frac{f_{c, e f f}}{\varepsilon_{3, p, e f f}} & \text { if } \varepsilon_{1, s b}>\bar{\varepsilon}_{1, p},
\end{array}\right.
$$

where $f_{c, \text { eff }}$ is calculated by replacing $\varepsilon_{3, p, \text { eff }}$ directly in Equation (A4):

$$
f_{c, e f f}=(\bar{\alpha}-1) \frac{\varepsilon_{3, p, e f f} \cdot E_{c}}{\bar{\alpha}-1+\left(\frac{\varepsilon_{3, p, p e f f}}{\bar{\varepsilon}_{3, p}}\right) \bar{\alpha}} .
$$

